\title{
Wirkungen des pleistozänen kaltzeitlichen Klimas, insbesondere des Bodenfrostes, in den Sedimenten des östlichen Ostfalen (Raum Hannover - Wolfsburg - Helmstedt - Bad Harzburg - Salzgitter-Bad - Hannover) - Teil 1
}

\author{
KARL-UlRICH BrosCHE*) \\ Lower Pleistocene, eastern part of Lower Saxonia, Saalian and Weichselian deposits, diversified solifluction \\ layers, horizons of gelifraction, congelifracts, glacigen structures, forms of cryoturbation, depth of former mollisol
}

\begin{abstract}
Kurzfassung: In diesem ersten Teil wird der reichhaltige Formenschatz von gegliederten periglazialen Solifluktionsschuttdecken, von Gelifraktionshorizonten, Kongelifraktaten, Frostkesseln, geologischen „Stichen“, des Hakenschlagens, von glazigenen Strukturen der Eisstauchung und von Kryoturbationsformen im östlichen Ostfalen (östlicher Teil von Niedersachsen) abgebildet, beschrieben, gedeutet und datiert. Die meisten Formen treten in wahrscheinlich saalezeitlichen (drenthezeitlichen) glazifluvialen und moränalen Lockersedimenten auf, die südlich der nördlichen das Gebiet zerschneidenden Lößgrenze von einer meist dünnen Lößschicht überdeckt werden. Diese hochglaziale weichselzeitliche Lößschicht dient zur Datierung der gegliederten Solifluktionsschichten und der vielen im Gebiet gefundenen Kryoturbationsformen. In aller Regel muß deren Bildung bereits im zweiten Teil der Saalekaltzeit begonnen haben. Aus der Tiefe, bis zu der die Kryoturbationsformen hinabreichen, wird ein saalezeitlicher und weichselzeitlicher Auftauboden von 1,0 bis 1,5 m erschlossen.
\end{abstract}

[Action of pleistocene cold climate, especially of soil frost in the sediments of eastern Ostfalen - region of Hannover - Wolfsburg - Helmstedt - Bad Harzburg Salzgitter-Bad - Hannover]

Abstract: In this first part of the publication - a second part especially about ice-wedges and aeolian processes will follow in the next year - the abundant form inventory of diversified periglacial solifluction layers, of horizons of gelifraction, of congelifractates, of frost kettles "Frostkessel", geologic "Stiche", of the "Hakenschlagen", of glacigen structures of icefoldings and of cryoturbation structures in eastern Lower Saxony (eastern part of Ostfalen) is photographed, described, explained and dated. Most parts of the forms can be found in probably Saalian (Drenthe) glacifluvial and morainic sediments. In the southern part of the loess border which divides the researched region in a northern and a southern part, the Saalian sediments are covered by loessic sediments of high Weichselian age. The loessic deposits are used for the datation of the older diversified solifluction layers as well as for the many cryoturbation phenomena. Mostly the formation of the latter sediments has just begun in the second part of the Saalian time. Rec-

*) Anschrift des Verfassers: Prof. Dr. K.-U. Brosche, Institut f. Geographische Wissenschaften der Freien Universität Berlin, Fachrichtung Physische Geographie, Grunewaldstr. 35, 12165 Berlin ording to the depth where the cryoturbation phenomena reach down, the mollisol in top of the permafrost had had an extensure of 1,0 to 1,5 $\mathrm{m}$ during the Upper Saalian and the whole Weichselian period.

\section{Einleitung: Gegenstand der Untersuchung und Literaturübersicht}

Die Wirkungen des pleistozänen kaltzeitlichen Klimas, insbesondere des Bodenfrostes, sind im Untersuchungsgebiet recht zahlreich und vielgestaltig. Besonders im engeren Untersuchungsgebiet, im Raum zwischen Oker und der ehemaligen Zonengrenze bei Helmstedt, wo über viele Jahre sämtliche Aufschlüsse, auch im Bereich der verschiedenen Braunkohlentagebaue zwischen Helmstedt und Schöningen, untersucht wurden, war die Formenfülle äußerst vielfältig. Das lag ebenso an den besonders günstigen Aufschlußverhältnissen in den Tagebauen wie an der geologischen Vielfalt der Fest- und Lockergesteine.

Während in der Karte von KAISER (1960, Tafel I), die auch in erweiterter Form bei WASHBURN (1979: 296) veröffentlicht wurde, nur aus dem Bereich des Okertales Eintragungen für würm-und rißzeitliche Kryoturbationsformen vorliegen, die auf den Arbeiten von POSER (1947 a, b, 1948 a, b, 195i) beruhen, kann in der vorliegenden Arbeit und in einer dem Teil II beigefügten Karte ein reichhaltiges periglaziales Formeninventar dargestellt werden: Es weist gegliederte Solifluktionsschuttdecken, Gelifraktionshorizonte, Kongelifraktate, Frostkessel, tektonische Stiche, Formen des Hakenschlagens, glazigene Strukturen der Eisstauchung, Kryoturbationsformen, epi- und syngenetische Eiskeile, Vorkommen des Geschiebedecksandes, Deflationspflaster, Vorkommen von Sand-Löß-Verzahnung und einige asymmetrische Täler auf. Über Pingos, wie LoOK (1968) ein Exemplar im Ostelm gefunden zu haben glaubt, wird hier nicht berichtet.

Die Untersuchungen wurden in den 60er Jahren begonnen (BROSCHE 1964), als es noch viele kleinere Sand- und Kiesgruben sowie etliche kleinere Ziege- 
leien gab. Sie wurden später immer wieder im Zuge von lößstratigraphischen Studien und Untersuchungen zur pleistozän-kaltzeitlichen Formung (BROSCHE \& Walther 1978, 1991; Walther \& Brosche 1983) fortgesetzt und aktualisiert. In den Jahren 1993 und 1994 wurde das gesamte Untersuchungsgebiet noch einmal abgesucht.

Aus der weiteren Umgebung liegen besonders aus dem Elbetal bei Magdeburg (BRÜNING 1956 bis 1959) und aus dem nordöstlichen Harzvorland im Bereich der ehemaligen DDR Untersuchungsergebnisse zu der Themenstellung vor (Ludwig 1958; KaISER 1966; Mania \& Toepfer 1973; Mania 1965, 1967; Mania \& STECHEMESSER 1970).

Die Zusammenstellung des Formeninventars in Teil II, Karte 1, erhebt keinen Anspruch auf Vollständigkeit, was die Darstellung von Gelifraktionshorizonten, der Vorkommen von Kongelifraktaten, von Steinsohlen und von Geschiebedecksand betrifft. Auf die Lößstratigraphie und auf Eiskeilhorizonte wird nur kurz eingegangen (Teil II). Hierzu liegen bereits grundlegende Arbeiten vor, die sich entweder ganz auf den Untersuchungsraum beziehen (Bartels \& Rohdenburg 1968, Brosche \& Walther 1978) oder diesen einbeziehen (ROHDENBURG \& MEYER 1966; ROHDENBURg 1966; Walther 1979; Walther \& Brosche 1983; Brosche \& Walther 1991).

Das Untersuchungsgebiet weist wie die „Geologische Meile" am nördlichen Harzrand bei Goslar nahezu alle Fest- und Lockergesteine des Mesozoikums sowie verschiedene Lockergesteine des Tertiärs (des Eozäns, Oligozäns und Miozäns) sowie mittelpleistozäne glazigene und glazifluviatile Gesteine von der Elster-Kaltzeit bis zum Rehburger Stadium der Saale-Kaltzeit auf. Markante Schichtkämme und Schichtstufen, aber auch weniger imposante Schichtschwellen und Schichtrücken sowie Schichtrampen werden von weiten jungtertiären, wenig zertalten Rumpfflächen unterbrochen, die sich z. T. eng an die alttertiären Rumpfflächen anlehnen (Herrmann 1929; Brosche 1968, 1969 a). Diese werden von überwiegend dünnen quartären Deckschichten einschließlich von meistens würmzeitlichem (an manchen Stellen von Resten saaleund vielleicht auch elsterzeitlichem) Löß überlagert (Brosche \& Walther 1991). Die nördliche Lößgrenze zieht in W-E-Richtung von Hannover über Braunschweig - Helmstedt - Magdeburg mitten durch das Untersuchungsgebiet (vgl. Poser 1951; MerkT 1968; LIEDTKE 1975).

\section{Frostsprengung, Kongelifraktate, Gelivationshorizonte, Frostkessel, „Stich“, Hakenschlagen und Solifluktion}

Zeugen der Frost sprengung fanden sich in erster Linie in allen Festgesteinen des Mesozoikums, kaum dagegen in tertiären Gesteinen. Hier konnte dieses Phänomen nur in den Septarien des Mitteloligozäns beobachtet werden (in der ehemaligen Ziegeleigrube Stegemann im Bereich des heutigen Tagebaus Helmstedt der Braunschweigische Kohlebergwerke AG Helmstedt - BKB). Alle übrigen tertiären Gesteine, die kilometerweit in den Tagebauen bei Helm-

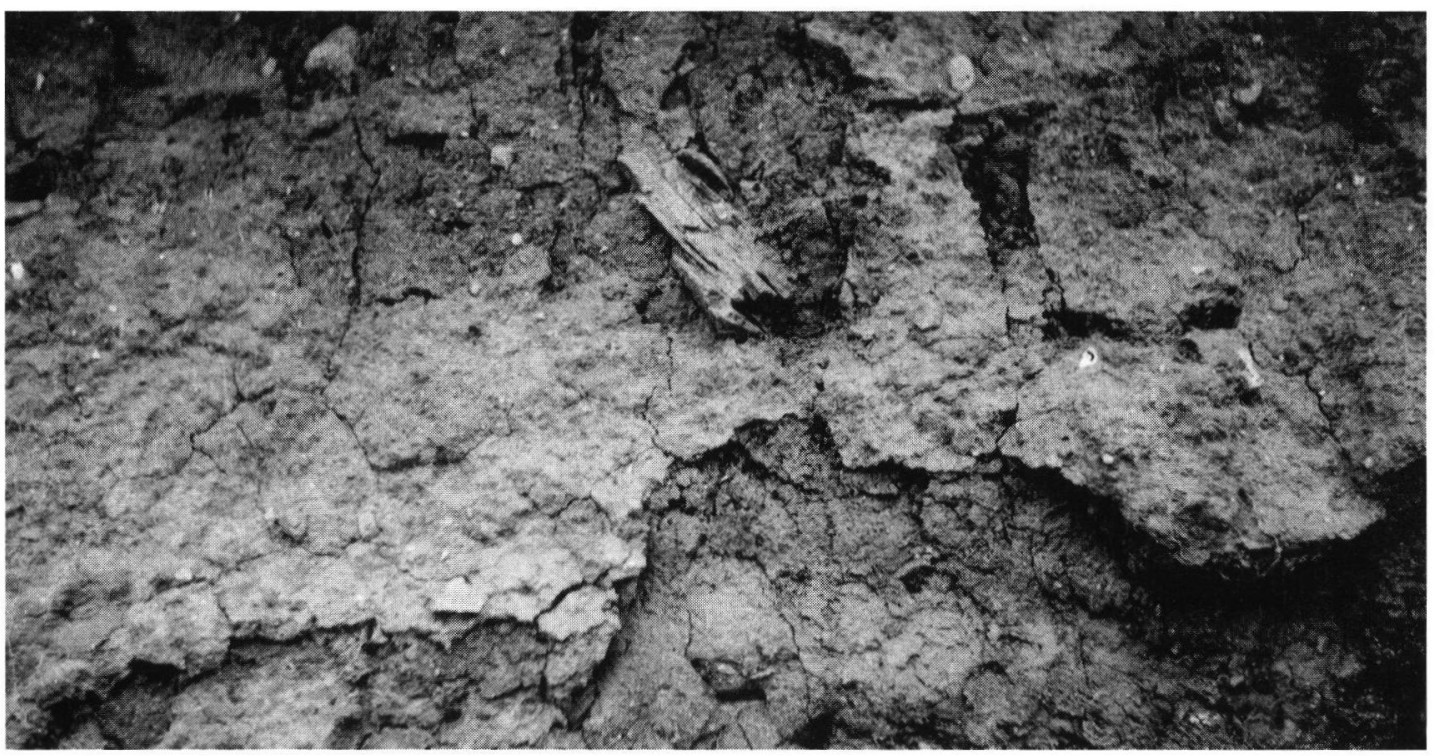

Abb. 1: Ca. $10 \mathrm{~cm}$ langes Kongelifraktat (kristalliner Schiefer) in sandig-lehmiger Grundmoräne, ca. $1 \mathrm{~m}$ unter der Oberfläche. Ehemalige Tongrube der Stegemannschen Ziegeleigrube am Silberberg südl. Helmstedt (heute Tagebau Helmstedt der Braunschweigische Kohlenbergwerke AG). Foto Sommer 1963.

Fig. 1: Frost-shattered rock in a Drenthe moraine ("Kongelifraktat") $1 \mathrm{~m}$ below the surface. Former till factory Stegemann south of Helmstedt (Lower Saxony). Photo summer 1965. 


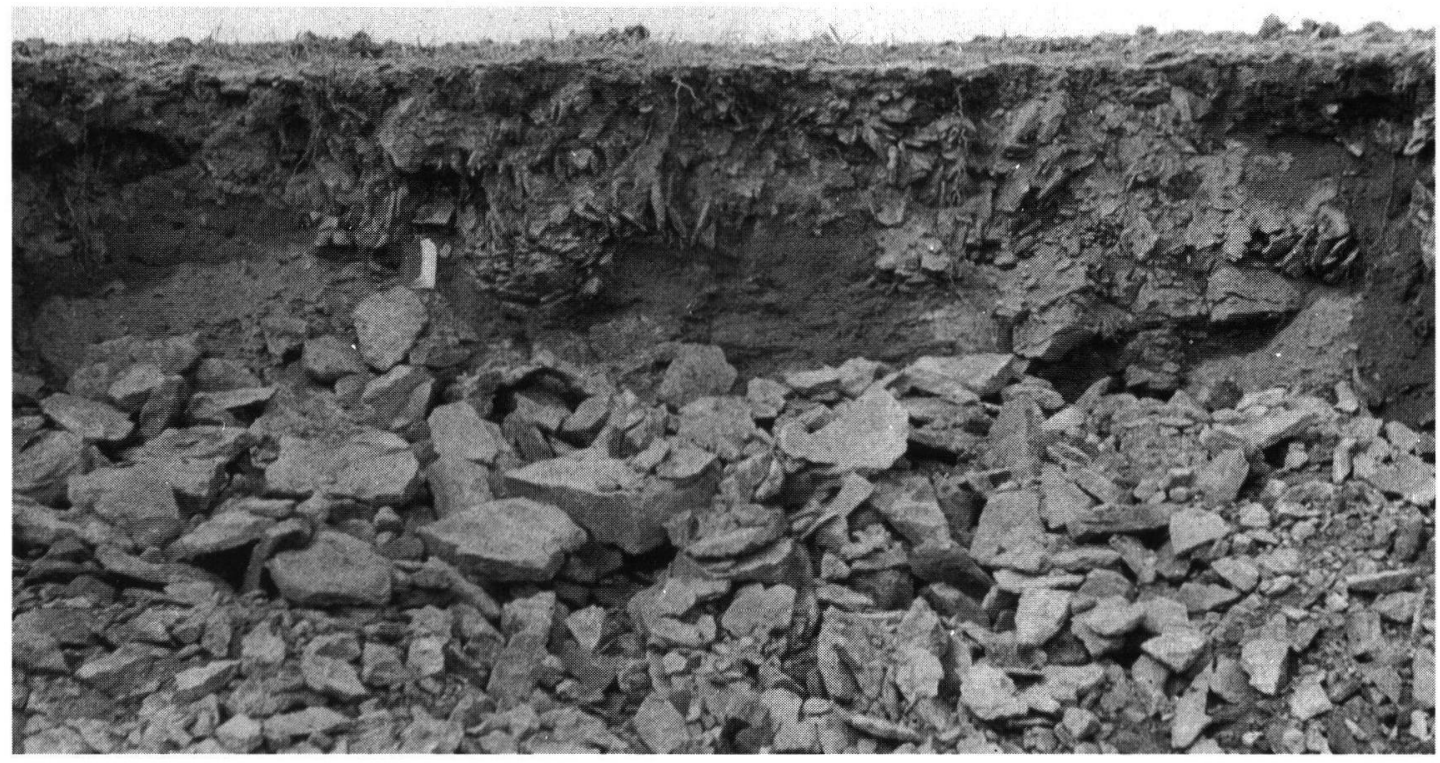

Abb. 2: Baugrube westl. Harenberg westl. Hannover im Doggersandstein mit kräftigem Gelivationshorizont und Frostkesseln. Maßstab ein $14,5 \mathrm{~cm}$ langes Notizbuch. Gelivationshorizont in lößfreiem Gebiet 0,6 - 0,7 m mächtig. Bemerkenswert die Steilstellung der plattigen Sandsteine. Foto Sommer 1965.

Fig. 2: Gelivation horizon in Dogger-sandstone west of the village Harenberg (west of Hannover). Even a "Frostkessel" can be observed. Photo summer 1965.

stedt aufgeschlossen sind, sind so feinkörnig, daß makroskopisch keine Frostsprengungserscheinungen erkennbar waren.

Während in Gelivationshorizonten, wie ein Beispiel in Abb. 2 dargestellt ist, nicht genau entschieden werden kann, welcher Anteil der Frostsprengung dem gegenwärtigen holozänen Klima und welcher der pleistozän-kaltzeitlichen Frostsprengung zuzuschreiben ist, ist diese Entscheidung an Steinbruchwänden im Rätsandstein (z. B. im Lappwald bei Helmstedt bzw. im Velpker Gebiet) oder in Muschelkalksteinbrüchen im Elm, aber auch an Absitzschollen im Unteren Muschelkalk des Elm, die GOEDECKE (1966: 38 ff.) genauer beschrieben hat, einwandfrei zu fällen. Auf eine kartographische Darstellung des weit verbreiteten Phänomens der eiszeitlichen und rezenten Frostsprengung wurde verzichtet (s. o.). Lediglich das in dieser Arbeit abgebildete Beispiel zum Kapitel 2 wurde in Tafel I (Teil II) eingetragen.

Die deutlichsten Anzeichen von Frostsprengung wurden in tonig-siltig-sandig-steinigen Grundmoränenablagerungen in der Umgebung von Helmstedt gefunden. Abbildung 1 zeigt ein Kongelifraktat im kristallinen Schiefer in einer typischen Grundmoräne in der ehemaligen Tongrube Stegemann südlich von Helmstedt (im Bereich des heutigen Tagebaus Helmstedt der BKB). Das Kongelifraktat, unter einer ca. $1 \mathrm{~m}$ mächtigen Lößdecke in der Grundmoräne gelegen, ist ca. $10 \mathrm{~cm}$ lang. Deutlich ist die Zersplitterung des Steins zu erkennen, wobei anzu- nehmen ist, daß die Frostsprengung schon vor Ablagerung des würmzeitlichen Lösses während der Saale-Kaltzeit (nach dem Drenthe-Maximalvorstoß) erfolgt ist.

Der in Abb. 2 dargestellte Gelivationshorizont bei Harenberg (westl. Hannover) ist das eindrucksvollste Beispiel für die Dokumentation der Einwirkung des eiszeitlichen Klimas auf bankige Festgesteine. Er wurde hier als Belegmaterial allerdings auch deshalb abgebildet, weil er gleichzeitig frostkesselartige Strukturen dokumentiert, die bereits Sonderformen von Kryoturbationserscheinungen darstellen. Der eindrucksvollste Frostkes se 1, der in Abb. 2 rechts neben dem Notizbuch zu erkennen ist, verdankt seine Existenz offenbar u. a. dem Umstand, daß hier unterhalb des in Oberflächennähe anstehenden Doggersandsteins eine recht sandige mürbe Zone innerhalb des Doggersandsteins auftritt, die ein Eindringen von Steinen von oben nach unten erlaubte. Die hier abgebildeten Frostkessel, die steilgestellten Steine und der gesamte Gelivationshorizont finden eine Parallele in von Hempel (1955) aus dem Göttinger Wald mitgeteilten Befunden aus dem Mittleren Buntsandstein. Zu echten Strukturböden (etwa Feinschutt-Grobschutt-Streifen) ist es hier allerdings noch nicht gekommen.

Im ehemaligen kleinen Tagebau östlich von Rottorf am Klei (nordwestl. Helmstedt), wo während des letzten Krieges Eisensandstein des Lias abgebaut wurde, befindet sich an der niedrigen Nordwand ein typischer Gelivationshorizont (Abb. 3). Die Gelivati- 


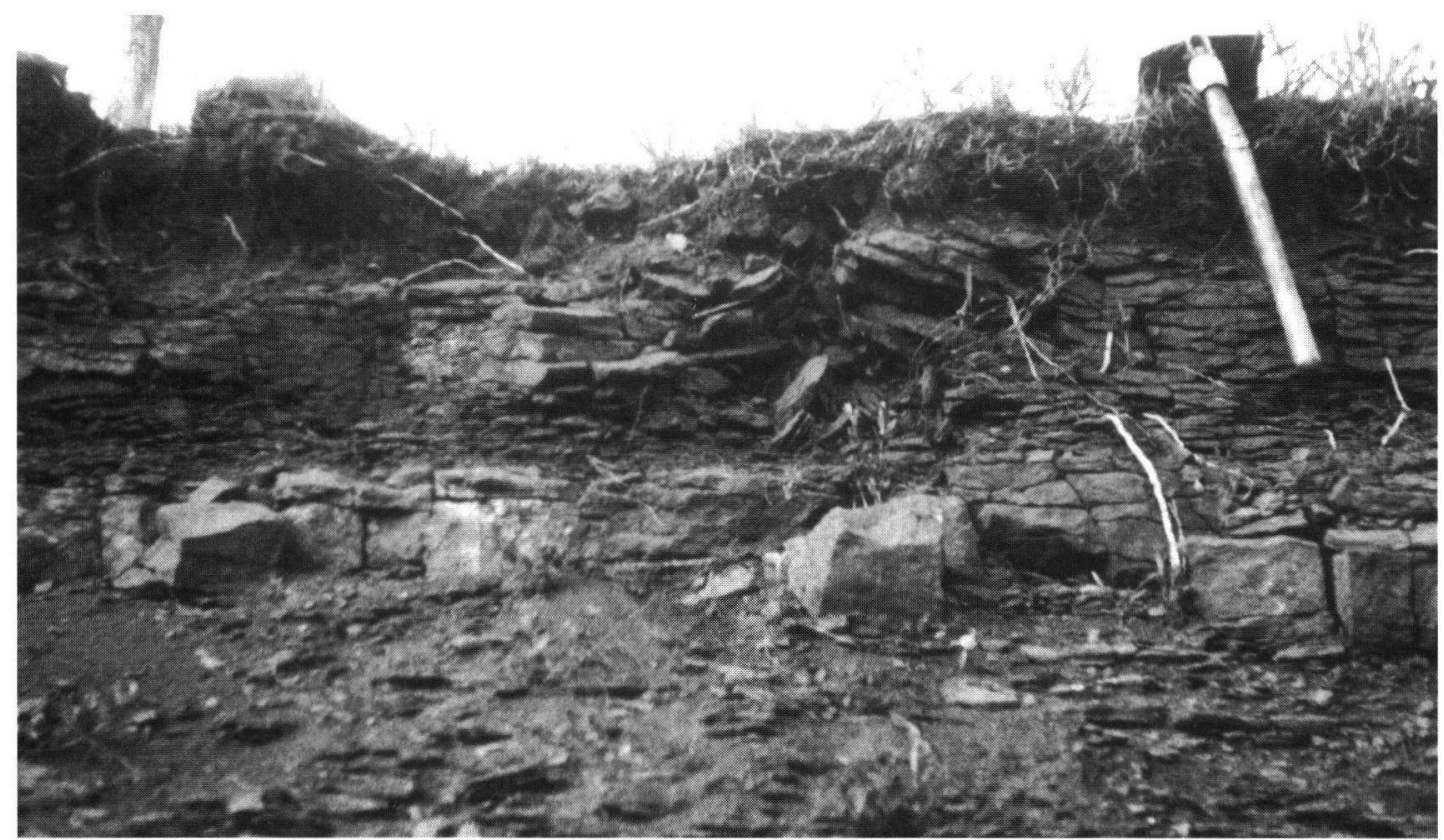

Abb. 3: „Stich“ i. S. KeilHacks (1931) im ehemaligen Eisensandsteintagebau bei Rottorf am Klei (nordwestl. Helmstedt). Neben dem Stich ein Gelivationshorizont in mürbem rotem Sandstein von ca. 0.5 m Dicke. Foto Sommer 1965.

Fig. 3: Geological "Stich" in the sense of KeILHACk (1931) in the former iron sandstone-mine near Rottorf at the Klei (northwest of Helmstedt). In the height of the geological "Stich" a horizon of gelivation in the frost-shattered red sandstone of Lias with a thickness of $0.5 \mathrm{~m}$. Photo summer 1965 .

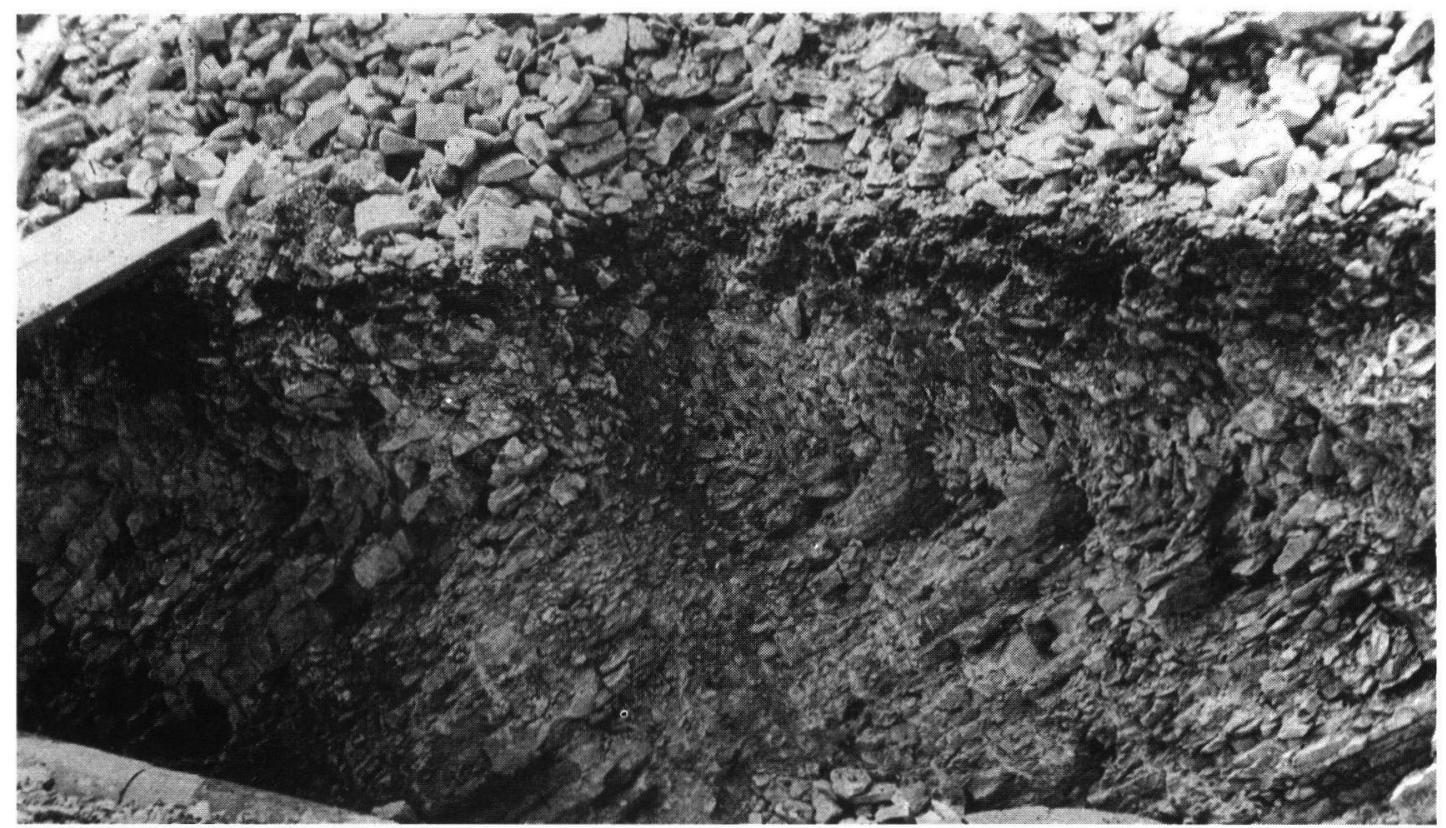

Abb. 4: Hakenschlagen im Sandstein des Mittleren Buntsandsteins am Friedhof nordwestlich Salzgitter-Bad im Salzgitterer Höhenzug (südl. des Hamberges). Höhe der Aufschlußwand 1,3 - 1,5 m. Oberes Fünftel des Fotos zeigt Auswurfmassen, darunter Braunerde-Ranker. Hakenschlagen auf dem nur 2 - $3^{\circ}$ geneigten Hang von rechts nach links verlaufend. Foto Sommer 1966.

Fig. 4: "Hakenschlagen" in sandstone of the "Mittlere Buntsandstein" at the cemitary of Salzgitter-Bad (Lower Saxony), northwest of the town. Height of the exposure 1,3-1,5 m. Upper part of the photo shows material artificially thrown out by the workers. The dark line near the surface shows a "Braunerde-Ranker". The "Hakenschlagen" on the slope with an inclination of $2-3^{\circ}$ is visible from the right hand side to the left. Photo summer 1966. 
on hat etwa den obersten Meter ergriffen. Innerhalb dieses Gelivationshorizontes fand ich innerhalb des Untersuchungsgebietes die einzige atektonische Faltung, einen „Stich“ i. S. KeIlHacks (1931). Die links neben dem Klappspaten sichtbare Struktur ist fast symmetrisch und erinnert etwas an einen oben geköpften Weihnachtsbaum. Der Frostdruck muß bei der Entstehung dieser fast einzigartigen Strúktur von unten nach oben - wahrscheinlich über einem Dauerfrostboden gewirkt haben. Es ist anzunehmen, daß eine ehemalige Eislinse sich so vergrößerte, daß die Schichten durch sie nach oben geschleppt wurden. Um echte Tektonik kann es sich bei der Entstehung der Struktur ebensowenig gehandelt haben wie um die Tätigkeit von Wühltieren, da hierfür keinerlei Anhaltspunkte vorliegen. Die obersten Steine des "Stiches" reichen in eine mäßig mächtige Braunerde hinein.

Hakenschlagen, das diesen Namen wirklich verdient, wurde im Untersuchungsgebiet nur einmal angetroffen (Abb. 4). Am Friedhof von SalzgitterBad im Südteil des Hamberges $(275,5$ m) wurde 1966 ein Graben gezogen, um Abflußrohre zu installieren. Der Mittlere Buntsandstein fällt hier mit ca. $50^{\circ}$ ein, der Hang ist nur $2-3^{\circ}$ geneigt. Der dunkle braune Horizont ist ein Braunerderanker über einer aus Buntsandstein bestehenden Schuttdecke. Oberhalb des braunen Bodens befindet sich Auswurfmaterial (helle Steine). Die Höhe des Aufschlusses beträgt 1,3-1,5 m. Deutlich ist zu erkennen, wie im gesamten Aufschluß der dünnbankige Mittlere Buntsandstein hangabwärts verschleppt worden ist. Die umgebogenen Sandsteinschichten lösten sich in klassischer Weise zu einer Schuttdecke auf und wurden in die Solifluktionsschuttdecke einbezogen. Wahrscheinlich hat dieser Vorgang während langer Zeiträume innerhalb der Kaltzeiten wirken können. Glazigene oder eiszeitliche Decksedimente gibt es hier nicht. Sofern sie vorhanden waren, sind sie wieder abgetragen worden.

Eindeutig als Solifluktionsschuttdecken einzustufende Wanderschutt- bzw. Fließerdedecken findet man flächenhaft innerhalb des Untersuchungsgebietes nur in den Höhenzügen, wie z. B. im Lappwald bei Helmstedt (vgl. Brosche 1964), im Rieseberg, im Dorm, im Harliberg, im Salzgitterer Höhenzug, in den Lichtenbergen, im Höhenzug Galgenberg-Vorholz, in der Asse, am Ösel bei Wolfenbüttel, in der Asse-Fortsetzung und im Heeseberg (BRosche 1968) sowie im Elm (GOEDECKE 1966). Hangneigungen von mindestens $2-3^{\circ}$ (in Ausnahmefällen), meistens aber von $4-5^{\circ}$ sind i. a. die Voraussetzung für

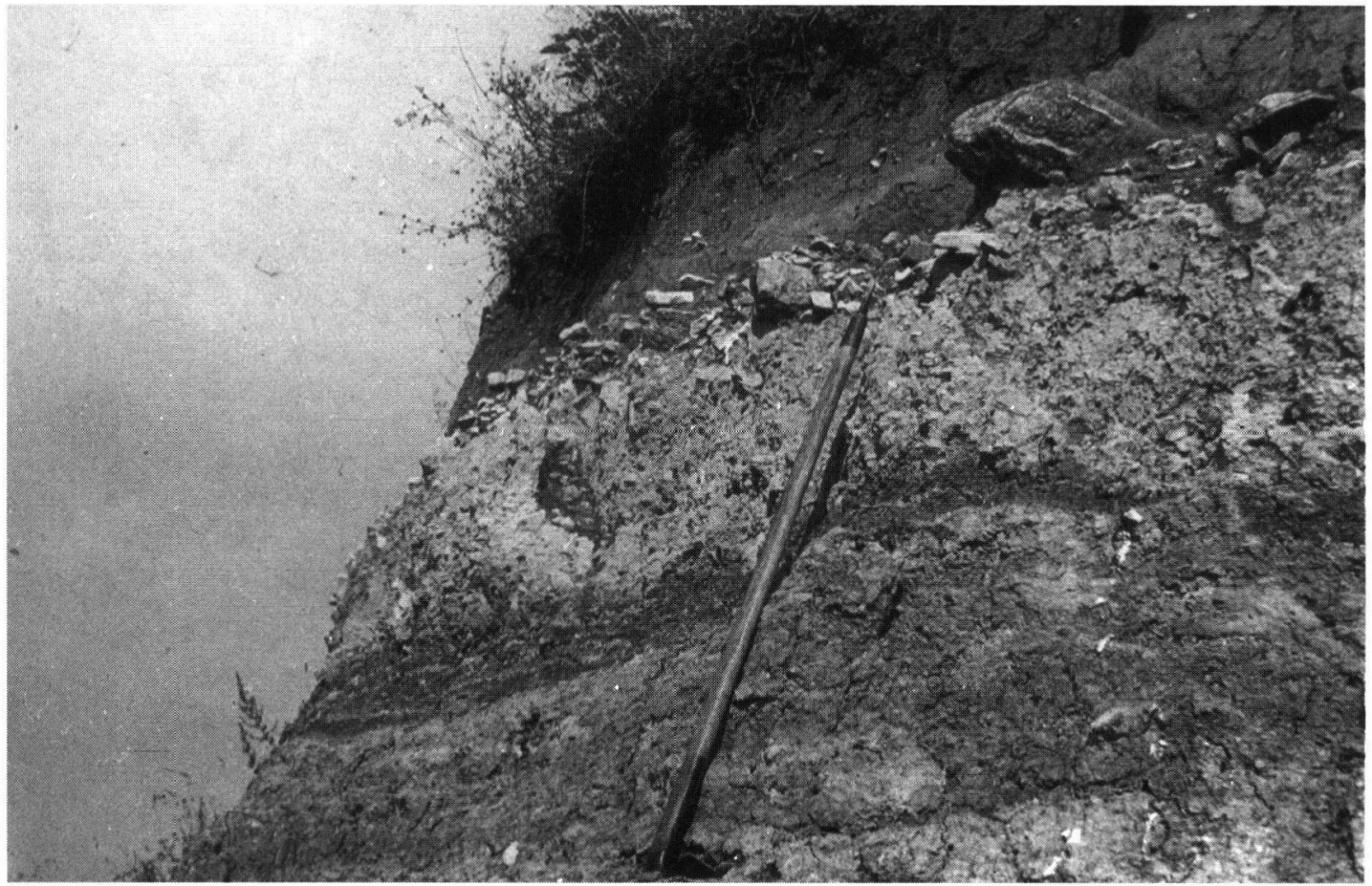

Abb. 5: Kalksteinbruch nordöstl. des Heeseberges (südwestl. Schöningen). Im unteren Drittel anstehendęr roter Ton des Mittleren Muschelkalks. Im oberen Teil des Eispickels Fließerdedecke des Wellenkalks. Darüber im Hangenden wahrscheinlich drenthezeitliche Grundmoräne mit Wellenkalkbrocken. Eispickel 0,8 m. Foto Sommer 1994.

Fig. 5: Chalk exposure northeast of the Heeseberg (southwest of Schöningen). In the lower third part of the photo not moved red marl of the very seldom exposured "Mittlere Muschelkalk". In the upper part of the ice-pimple ("Eispickel") solifluction layer of the "Untere Muschelkalk". Above the ice-pimple probably Drenthe moraine (Grundmoräne) with pieces of stones of the "Untere Muschelkalk". Length of the ice-pimple 0,8 m. Photo summer 1994. 
flächenhaftes Bodenfließen, das in Abhängigkeit vom Gestein unterschiedlich intensiv war. Auf die Darstellung der eiszeitlichen Solifluktionsschuttdecken wird in Tafel I des Teils 2 verzichtet (s. o.). Viel schwieriger ist der Nachweis von Wanderschuttdecken in den glazigenen, glazifluvialen und äolischen Ablagerungen, die fast das ganze Untersuchungsgebiet in mehr oder weniger großer Mächtigkeit überkleiden. Löß tritt erst südlich der nördlichen Lößgrenze auf, die von Magdeburg nach Helmstedt verläuft, dabei das Stadtgebiet von Helmstedt quert (s. u.) und etwa parallel zur Bundesstraße 1 nach Braunschweig und Hannover zieht (vgl. Poser 1951; Merkt 1968; LiedtKe 1975). Bei Brosche \& WALTHER (1991) wird besonders im Rahmen von Lößuntersuchungen auf innerweichselzeitliche Lößbildungs-, Bodenbildungs- und Solifluktionsphasen eingegangen.

Im Rahmen dieses Beitrags soll lediglich auf ein Wanderschuttdeckenvorkommen nordöstlich des Heeseberges (südwestl. Schöningen) eingegangen werden, für das sich im Unterschied zu allen übrigen Vorkommen ein saalezeitliches, eventuell sogar ein elsterzeitliches Alter nachweisen läßt. Im Steinbruch des ehemaligen Hoiersdorfer Zementwerkes am Heeseberg zwischen Jerxheim und Watenstedt sind steil nach N einfallende Gesteine des Unteren Muschelkalks, der hier über mehrere Jahrzehnte ausgebeutet wurde, und in geringer Mächtigkeit Kalke, Mergel und Tone des Mittleren Muschelkalks (am Nordrand des Steinbruchs) aufgeschlossen. Der Untere Muschelkalk bildet hier keinen Schichtkamm, sondern eine flache Schichtschwelle i. S. Brosches (1968). Diese W - E verlaufende Schichtschwelle nördlich des Heeseberges wird sowohl auf der Nord- wie auch auf der Südseite von einem flachen subsequenten Tal begleitet. Zum nördlichen Tal hin besteht ein Gefälle von 2 $5^{\circ}$, das sich bezüglich des höheren Wertes nur schätzen bzw. aus der Karte entnehmen läßt, da die Vollform der Schichtschwelle wegen der Steinbruchausbeutung weitgehend verschwunden ist. Die Nordwand des Steinbruchs ist heute noch genauso gut aufgeschlossen wie vor 29 Jahren. Das Profil (Abb. 5) läßt im oberen Meter eine Grundmoräne mit hohen Schluffanteilen, Kalkschutt aus dem Elm und aus dem weiter nördlich anstehenden Oberen Buntsandstein und mit wenigen glazialen Geschieben erkennen (Schicht 1). Darunter folgt als Schicht 2 eine 0,6 m mächtige Solifluktionsschuttdecke aus Material des Unteren Muschelkalks; als eindeutige Wanderschuttdecke liegt sie auf einem solifluidal-laminar verflossenen Paket des Mittleren Muschelkalks (Schicht 3), auf das sie hinaufgeflossen ist. In dieser Muschelkalkwanderschuttdecke werden keine glazialen Geschiebe gefunden. Wie schon erwähnt, ist der obere Teil des Mittleren Muschelkalks laminar verflossen, was man besonders deutlich auf Abb. 5 erkennen kann (Mächtigkeit 0,5 m). Mit einem deutlichen Sprung grenzt sich die Solifluktionsschuttdecke des roten Mittleren Muschelkalks, der hier in Gestalt von Tonen und tonigen Mergeln auftritt, von dem anstehenden Mittleren Muschelkalk ab, der in Gestalt von grauen Mergeln, Tonen und dünnen Kalkschichten auftritt (Schicht 4). Unter dieser Schicht 4 folgt - in Abb. 5 nicht sichtbar - der Untere Muschelkalk, der das wirtschaftliche Interesse begründete. Aufgrund der geschilderten Sedimentverhältnisse hat sich sowohl die laminar verflossene Fließerdedecke des Mittleren Muschelkalks (Schicht 3) als auch die Fließerdedecke des Wellenkalks (Schicht 2) gebildet und bewegt, bevor die wahrscheinlich drenthezeitliche Moräne (Schicht 1) das Gebiet erreichte. Beide sind somit als prädrenthezeitlich einzustufen. Wie an der Muschelkalkschichtstufe am Ostrande des Sollings und Bramwaldes, die ROHDENBURG (1965) untersuchte, ist die Fließerdedecke des Mittleren Muschelkalks eher in eine feucht-kalte Phase zu stellen, während die Fließerdedecke des Wellenkalks eher in eine trocken-kalte Phase eingestuft wird. Abschließend sei bemerkt, daß dies die einzige Lokalität im Untersuchungsraum darstellt, an der der Mittlere Muschelkalk aufgeschlossen ist und sich eine so interessante Schichtenabfolge ergibt - die komplizierten Lößprofile (Brosche \& Walther 1991) einmal ausgenommen.

\section{Glazigene Strukturen sowie eine schwer deutbare Struktur}

Nach allgemeiner Auffassung liegt das Untersuchungsgebiet im Bereich des Drenthe-Eisvorstoßes, der bis an den Harzrand heranreichte und zumindest in das Innerstetal einige Kilometer hineinreichte. Vom Windmühlenberg bei Peine verläuft nach den Vorstellungen von WOLDSTEDT \& DUPHORN (1974) über die Höhe südlich Weddel (östl. Braunschweig) bis zum Galgenberg bei Bahrdorf (östl. Wolfsburg), nach den Vorstellungen von LоOK $(1967,1984)$ vom Weddeler Berg bis zum Elz (westl. Helmstedt), ein niedriger, oft unterbrochener Endmoränenzug, der dem Rehburger Stadium zugeordnet wurde. Das saalezeitliche (vielleicht auch das elsterzeitliche) Eis hat jedoch nicht nur in Gestalt von niedrigen Endmoränenwällen, oft sehr mächtigen glazifluviatilen Sedimenten und Grundmoränen seine Wirkung gezeigt, sondern an manchen Stellen, die gut aufgeschlossen waren, auch einen noch eindrucksvolleren Einfluß ausgeübt: Das erste Beispiel (Abb. 6) ist zwar nicht mit der Diskordanz in Bochum-Querenberg oder der Diskordanz zwischen Dresden und Freital identisch, wo Kreide auf Paläozoikum auflagert; aber er ist doch im Untersuchungsgebiet der einzige Aufschluß, der eozäne Sande, die an ihrer 


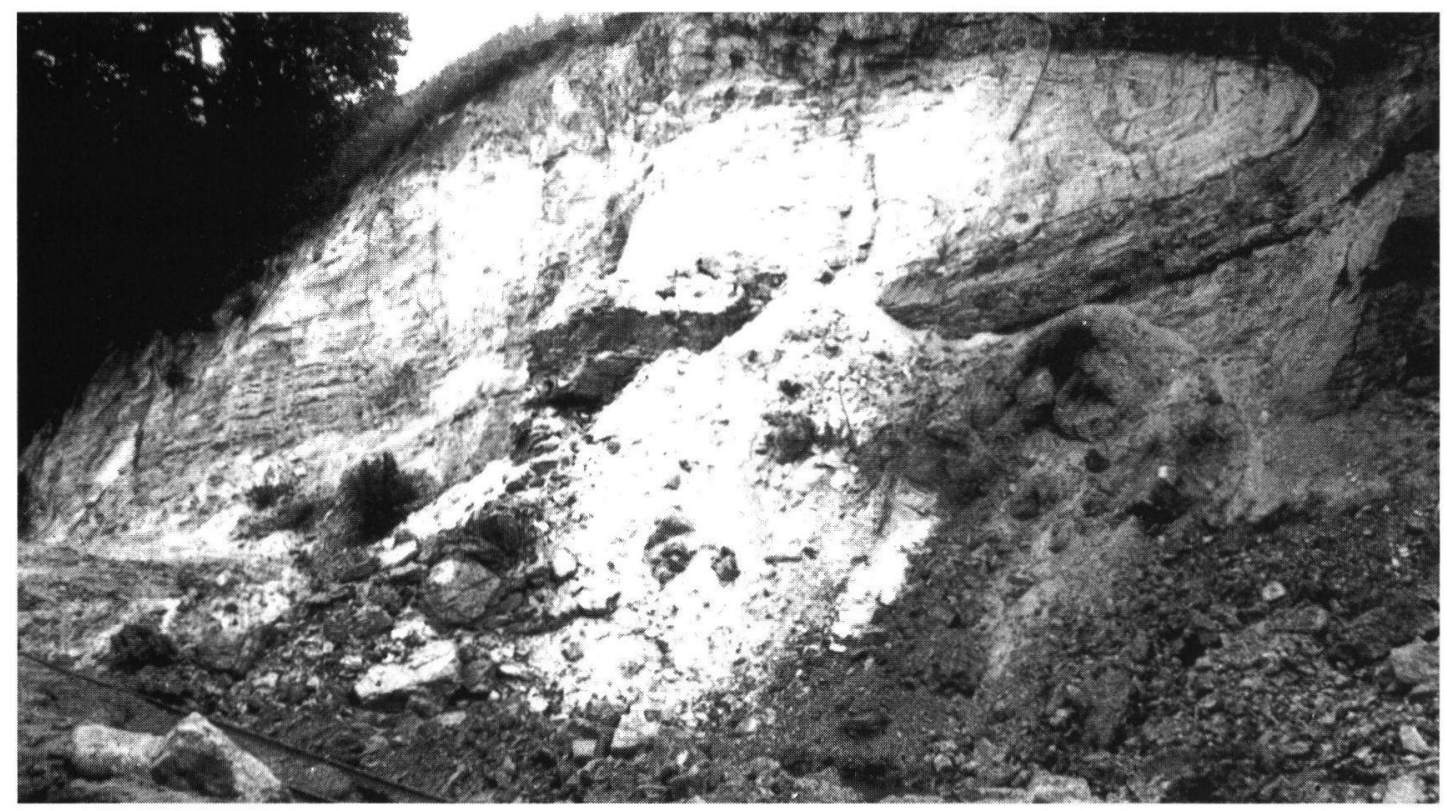

Abb. 6: Glazigene Falte im Westteil der ehemaligen Tongrube der Ziegelei Lehrmann am ehemaligen Helmstedter Ortsrand Richtung Emmerstedt. Helle feine Eozänsande (im Zentrum des Fotos), die sich auf Liastone der Lappwaldscholle auflagern (rechts unter dem Versturz), wurden von einem wahrscheinlich drenthezeitlichen Gletschervorstoß nach Südwesten an ihrem Top verschleppt und von Grundmoräne (im Zentrum im Top) überdeckt. Im rechten Teil der Falte das glazigene Hakenschlagen gut erkennbar. Foto Sommer 1966.

Fig. 6: Glacigenic fault in the western part of the former clay exposure of the brick factory Lehrmann at the former city border of the town of Helmstedt at the road Helmstedt - Emmerstedt. Light fine Eocenean sands (in the centre of the photo), which are discordantly lying on Liassic clays of the Lappwald (on the right hand side below the loose material). They were bended to the southwest. by a probably Drenthe icestream on their top and covered by morainic sediments (in the centre of the top). In the right part of the glacigenic fold the "Hakenschlagen" is very well visible. Photo summer 1966.

Basis von Sanden und roten Tonen gebildet werden, auf Liastonen (am rechten Bildrand in Bildmitte) diskordant auflagern läßt. Es handelt sich um das nördlichste Ende der östlichen Helmstedter Braunkohlenmulde, die in der ehemaligen Ziegeleigrube Lehrmann (nahe dem ehemaligen Bahnhof Emmerstedt bei Helmstedt) über mehrere Jahrzehnte in der dargestellten Form aufgeschlossen war. Man beobachtet hier ein Hakenschlagen, wie es deutlicher nicht sein kann, allerdings verursacht durch einen etwa aus NE erfolgten Gletschervorstoß, wahrscheinlich des Drentheeises. Nicht nur die gut geschichteten weißen Sande des Eozäns, sondern auch die erwähnten, an der Basis des Eozäns anzutreffenden roten Tone und hellen Sande wurden offenbar vom Eise umgebogen. Es kam dabei zur Vermischung der Grundmoräne, die nordische Geschiebe enthält, mit dem tonig-sandigen eozänen Basissediment. Um ein solifluidales $\mathrm{Hak}$ en schla gen kann es sich hierbei nicht handeln, weil der Schichtverband der hellen eozänen Sande völlig erhalten ist. Dies spricht eher dafür, daß der glazigene Einfluß geschah, als der Boden gefroren war. - Das Gelände ist außerdem heute nur wenig $\left(1-3^{\circ}\right)$ nach Westen geneigt, und auch die tonigen roten Basissedimente des Eozäns sind in ihren unteren Teilen ungestört.
Da wir uns nördlich der nördlichen Lößgrenze befinden, können Lößablagerungen keine weiteren Datierungshinweise geben.

Die eindeutigsten Beispiele für das Einwirken des wahrscheinlich drenthezeitlichen Eises auf den Untergrund lieferten die Nord- und Ostwand des ehemaligen Tagebaus Treue der BKB, der in den letzten Jahrzehnten mehr und mehr zugefüllt wurde. Abb. 7 entstand an der $\mathrm{N}$-Wand. Eine $2-3 \mathrm{~m}$ mächtige weichselzeitliche Lößschicht überzieht hier meist feine glazifluviatile Sedimente, die aus Schluff- und Sandschichten bestehen. Diese bedecken, was in der Abb. 7 nicht eindeutig sichtbar ist, unteroligozäne glaukonitische Grünsande. Das Bemerkenswerte bei der abgebildeten glazigenen Stauchung ist, daß bei der wahrscheinlich von rechts (NE) erfolgten Eisstauchung nicht nur eine schöne zusammenhängende Falte entstanden ist, sondern am Top der symmetrischen Falte eine Spezialfältelung, wie man sie nicht allzu häufig antreffen dürfte. Auch die Stauchungen rechts neben dem Scheitelpunkt der Hauptfalte sind bemerkenswert. In den Oberflächenformen bilden sich allerdings keine deutlichen Vollformen ab. Es wird auch hier angenommen, daß das Eis auf gefrorene Sedimente traf. Die Stauchungen sind wahrscheinlich in das Rehburger 


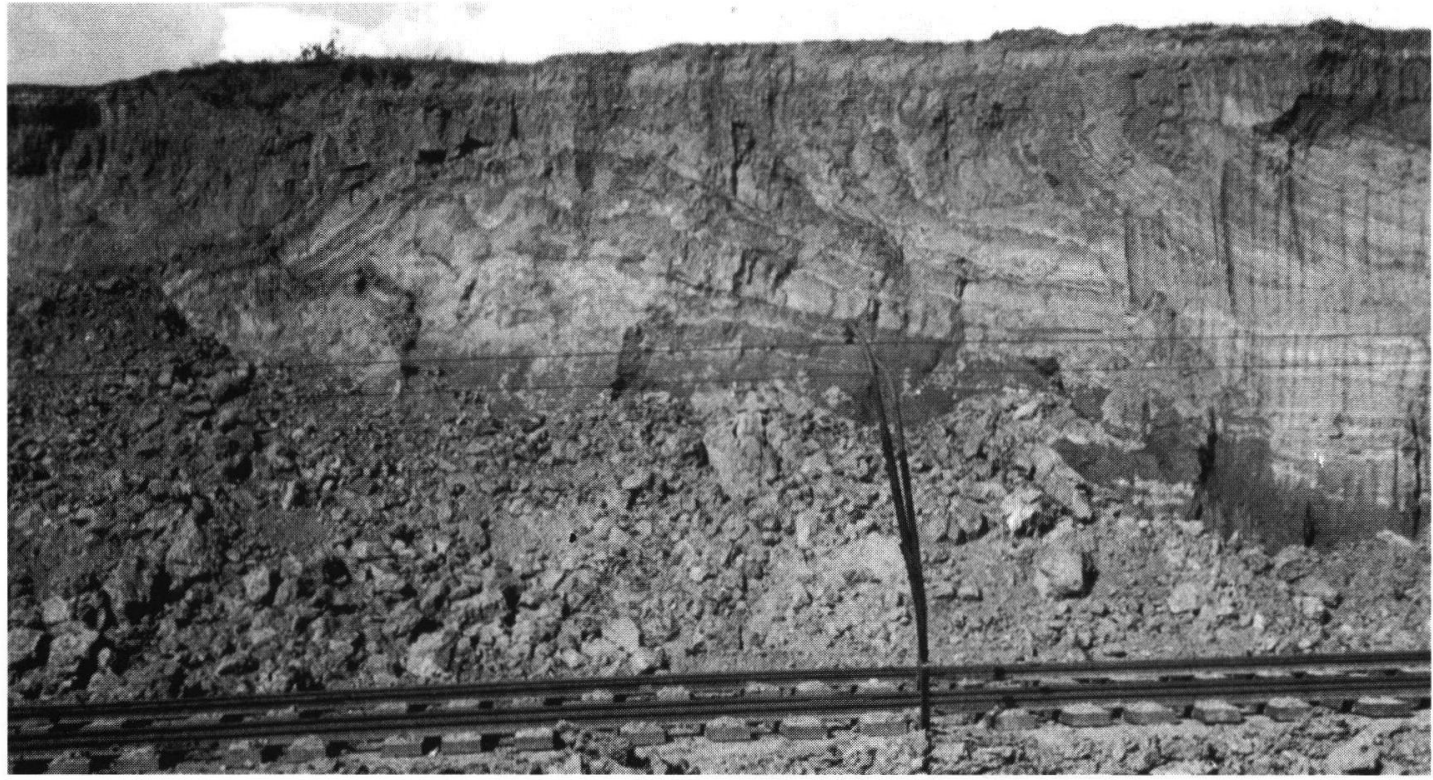

Abb. 7: Glazigene Falte in wahrscheinlich drenthezeitlichen Ablagerungen an der Nordwand des Tagebaus Treue der Braunschweigische Kohlenbergwerke AG Helmstedt. Bemerkenswert die Spezialfältelung im Sattel der Falte. Würmzeitlicher Löß lagert diskordant über den glazigenen Sedimenten. Dicke des Lösses: 2,0 - 3,0 m. Foto Sommer 1966.

Fig. 7: Glacigenic fold in probably Drenthe sediments at the northern ridge of the mine of Treue (Braunschweigische Kohlebergwerke AG Helmstedt). Note a special folding at the top of the fold. Würmian loessic sediments discordantly cover the glacigenic sediments. Thickness of the loess: 2,0 - 3,0 m. Photo summer 1966

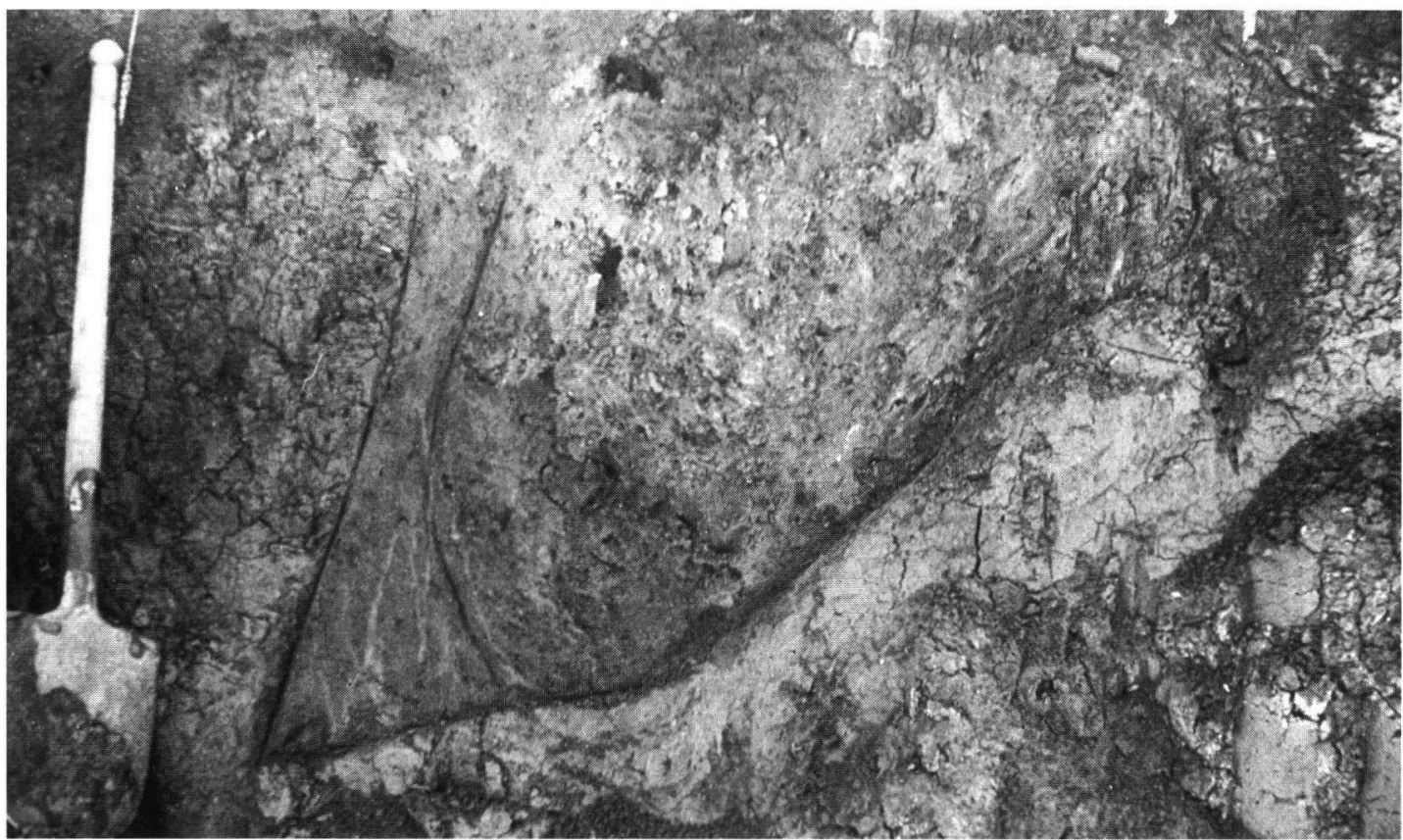

Abb. 8: Oberer Bildrand korrespondiert mit Geländeoberfläche. Kombination von eiskeilartigem Gebilde (rechts neben dem Spaten) und Kryoturbationskessel (künstlich umrandet). „Keil“ allerdings ohne Keilspitze. Lokalität: ehemalige Ziegeleigrube Stegemann am Ziegelberg nördl. Helmstedt, südl. der Autobahn, nahe der ehemaligen Abdeckerei. In Liastone ist das eigenartige Gebilde eingelassen. Foto Sommer 1965.

Fig. 8: Upper part of the photo correspondends with the landscape surface. Combination of icewedge-like form (at the right hand side of the spade) and a cryoturbation kettle (marked by a line by me). The ice-wedge-like form however without a tip. Locality: former clay exposure Stegemann at the Ziegelberg north of Helmstedt, south of the Autobahn, near the former Knacker's yard. The ice-wedge-like formation is immerged in the clay of Lias. Photo summer 1965. 
Stadium zu stellen, dem LooK $(1967,1984)$ in der nördlichen Nachbarschaft eine schwach entwickelte Endmoränenfolge zuordnet. An der Ostwand des ehemaligen Tagebaues Treue der BKB wurde eine hier nicht abgebildete halbkreisförmige, nach $\mathrm{N}$ geöffnete Falte in Grundmoränensedimenten aufgenommen, die ca. 3 - 5 m Durchmesser aufwies. Die Lößdeckschicht war an dieser Stelle künstlich abgeräumt worden. Hier hatte eine ursprünglich völlig schichtungslose, wahrscheinlich drenthezeitliche Grundmoräne eine „Stauchungsschichtung" erfahren, die in dieser Form im Untersuchungsgebiet einmalig war.

Es ist, was die Stauchungsbilder betrifft, fast alles bei glazigener Einwirkung möglich. Der Eisdruck ist an der Ostwand des Tagebaus Treue aus mehr oder weniger nördlicher Richtung erfolgt. Die Abbildung 7 und das eben beschriebene Aufschlußbild sind nur zwei Beispiele einer Vielzahl weiterer Stauchungsbilder im Tagebau Treue. Warum sie gerade hier und nicht in den Tagebauen Helmstedt und Alversdorf auftraten, dürfte an der Nähe der Endmoränen des Rehburger Stadiums liegen. Wahrscheinlich ist, daß der einige 100 Meter nördlich flach aufragende Elz bei Helmstedt Teilstück eines Stauchendmorä- nenzuges ist (LOOK 1967). Darauf weisen die geomorphologischen Formen hin; Aufschlüsse, die dies belegen, gibt es dort allerdings nicht.

Eine ebenfalls eindrucksvoll ausgeprägte symmetrische Stauchfalte, wie sie in Abb. 7 dargestellt ist, fand ich außerdem noch in der Sandgrube südlich Weddel, die zu dem vor 6 Jahren geschlossenen Kalksandsteinwerk Weddel gehörte. Sie ist in Abb. 13 erkennbar. Es handelt sich hierbei um die Ostwand der einstmals recht großen Sandgrube auf dem Weddeler Berg $(114,2 \mathrm{~m})$ der wahrscheinlich zum W-E verlaufenden Endmoränenzug des Rehburger Stadiums gehört. Der Höhenzug überragt die Umgebung um 10-20 m, was bei den sonst recht ausdruckslosen Oberflächenformen in Ostfalen bereits eine deutliche Reliefierung der Landschaft bedeutet. Obwohl der Eisdruck von links (Norden) gekommen sein muß, ist der nördliche Flügel der Falte flacher als der südliche, z. T. steil einfallende Flügel. Hier sind keine Grundmoränenablagerungen gestaucht worden, sondern überwiegend feine Sande und Schluffe, z. T. auch Kiese. Die Sandgrube, die jetzt andere Besitzer und Abnehmer hat, ist bis heute 200-300 m weiter nach Osten parallel zur Bundesstraße 1 gewandert. Auch heute findet man noch

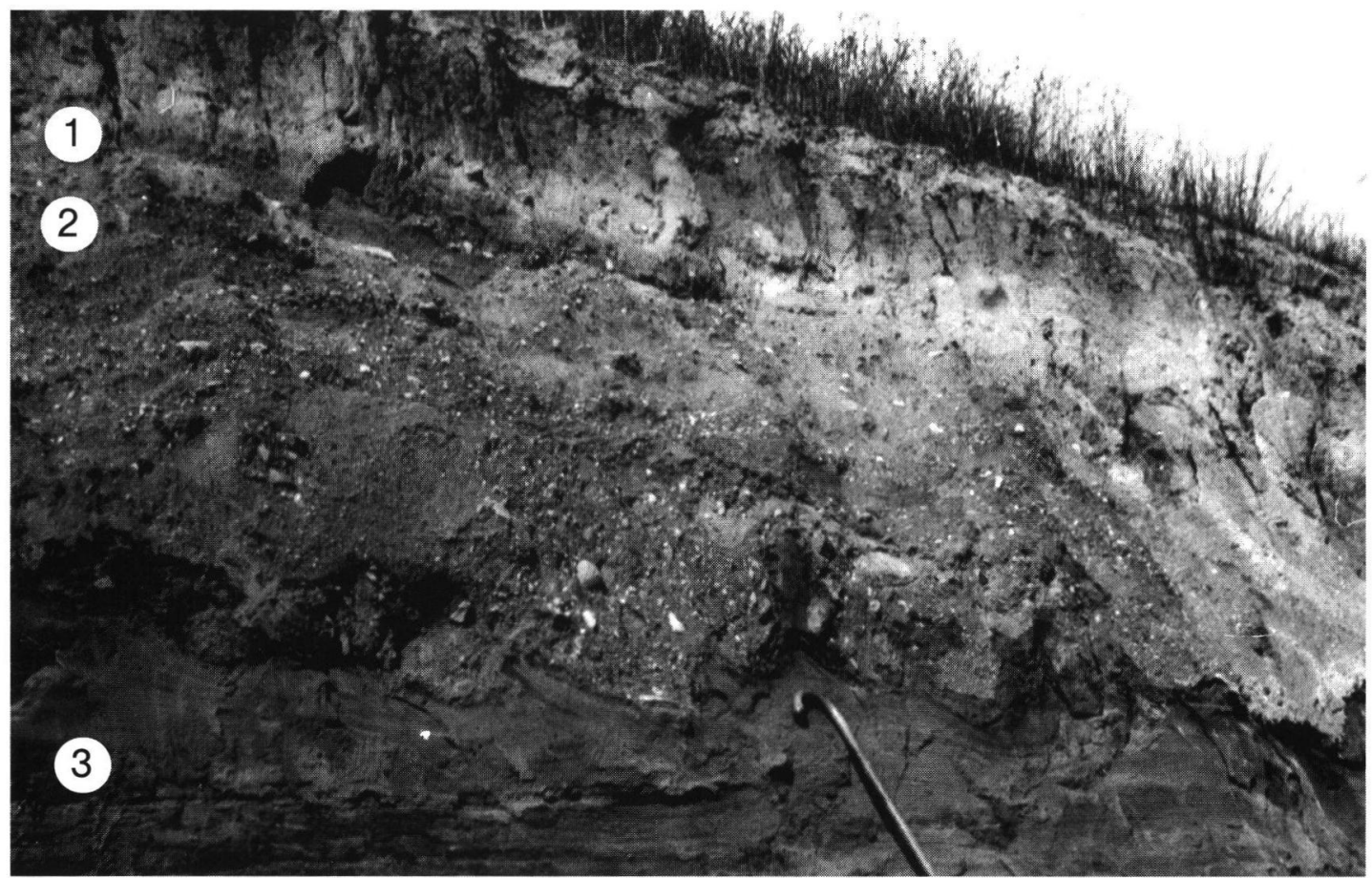

Abb. 9: Taschenboden an der Grenze von steinig-kiesiger Grundmoräne (wahrscheinlich drenthezeitlichen Alters) (Schicht 2) zu sandigen, z. T. etwas lehmigen glazifluvialen Sedimenten (Schicht 3). Im Hangenden (Schicht 1) würmzeitlicher Löß. Lokalität: Ehemalige Kiesgrube Evers nördl. der heutigen Landstraße Schöningen - Hötensleben (ca. 500 m von der ehemaligen Zonengrenze entfernt). Nordwand der Grube. Foto Sommer 1966.

Fig. 9: "Taschenboden" at the borderline of stony pebbled morainic sediments (probably of Drenthe age) (layer 2) to sandy, partly loamy glacifluvial sediments (layer 3). At the top (layer 1) wurmian loess. Locality: former pebble exposure Evers, north of the now existing road Schöningen-Hötensleben (in a distance of about $500 \mathrm{~m}$ from the former demarcation line), northern part of the exposure. Photo summer 1966. 


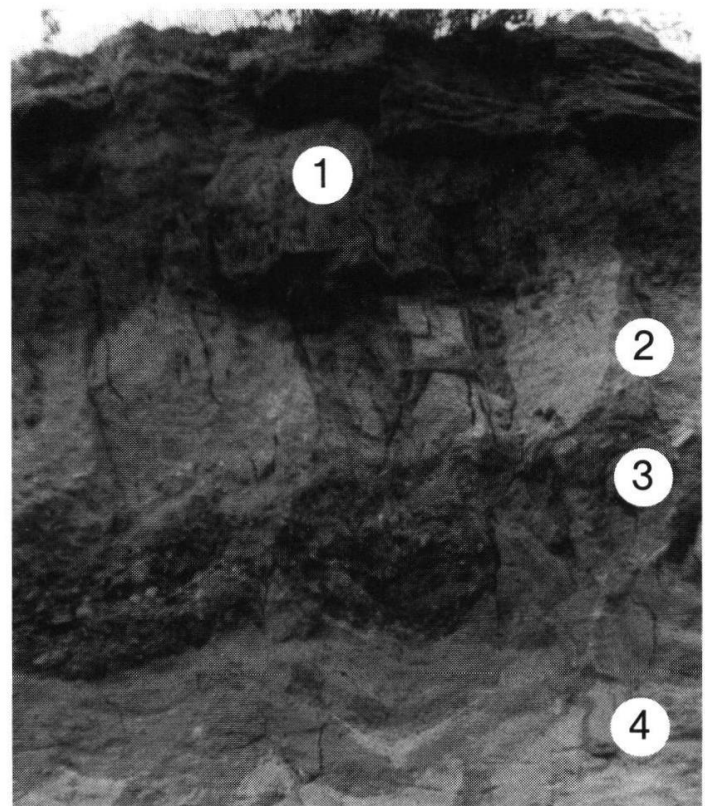

Abb. 10: Gleiche Lokalität wie Abb. 9. Taschen- und „Spitzenboden" mit liegenden Kryoturbationserscheinungen an der Schichtgrenze von gelbem Würmlöß (Schicht 2) zu Resten von wahrscheinlich drenthezeitlicher Grundmoräne (Schicht 3) und glazifluvialen Sanden und lehmigen dunkleren Sanden (Schicht 4). Im Hangenden Würmlöß mit Parabraunerde ( $\mathrm{B}_{\mathrm{t}}$ - Horizont unter der Eins). Foto Sommer 1966.

Fig. 10: Same locality as photo 9. "Taschen-" and "Spitzenboden" with forms of cryoturbation at the border of yellow loess of wurmian age (layer 2 ) to rests of probably Drenthe moraine (layer 3) and glacifluvial sands and loamy sands (layer 4). At the top wurmian loess with a Parabraunerde $\left(\mathrm{B}_{\mathrm{t}}\right.$ - horizon below the 1). Photo summer 1966.

Stauchungserscheinungen, allerdings nicht in der Klarheit der Abb. 13. Abschließend läßt sich feststellen, daß hier südlich Weddel die glazigene Stauchung zu einer Verstärkung des Reliefs in Gestalt von Stauchmoränen geführt hat.

Ein schwer deutbares Gebilde wurde in der ehemaligen Ziegeleigrube Stegemann Helmstedt (Grube am nördlichen Ortsrand von Helmstedt am Ziegelberg, nahe der Autobahn und der ehemaligen Abdeckerei) angetroffen. Liastone am NE-Rande der nördlichen Helmstedter Mulde werden hier stellenweise von Resten einer Grundmoräne überlagert. Das in Abb. 8 markierte Gebilde rechts neben dem Spaten unterscheidet sich vom Substrat her völlig von den Liastonen: Es besteht aus etwas lehmigen Sanden mit wenigen Steinen, einem stumpfen Keil links, einer steinigeren Übergangszone und aus einem Schutt mit sandiger Matrix. Die Steine zeigen hier häufig eine Steilstellung an. Sie bestehen zum geringen Teil aus nordischen Geschieben. Es ist zu vermuten, daß einerseits Eisdruck zu einem partiell stärkeren Eindringen von Moränenmaterial in den tonigen Untergrund geführt und andererseits auch später noch nach Abtauen des Eises Kryoturbation gewirkt hat. Hinzuzufügen ist, daß im Arbeitsgebiet mehrfach ein partiell tieferes Eindringen von Grundmoräne in glazifluviatile Sedimente (z. B. in der Kiesgrube Evers am Nordschacht bei Süpplingen) zu beobachten ist und man beim ersten Hinsehen auf die Wirkung von Kryoturbation tippt.

\section{Kryoturbationsformen}

Ziel der folgenden Darstellung ist es, die am besten entwickelten Formen der Kryoturbation im Untersuchungsgebiet abzubilden, sie zu beschreiben, zu deuten und zu datieren. Dabei ist immer zwischen dem lößfreien Nordteil des Untersuchungsgebietes und dem lößbedeckten Südteil zu unterscheiden. Trotz häufig wiederkehrender Schichtfolgen: würmzeitlicher Löß (1), sandig-kiesig-lehmige Grundmoräne (2) und glazifluviatile Sedimente (3) - vgl. Abb. 9 - trifft man Kryoturbationserscheinungen an der Schichtgrenze von 2 zu 3 selten in klarer Form an. In der ehemaligen Kiesgrube Evers nahe Hötensleben (Sachsen-Anhalt) an der ehemaligen Straße Schöningen - Hötensleben ist das liegende glazifluviale Sediment eher lehmig-sandig entwickelt. Die Schichtgrenze von (2) zu (3) lag vor der Ablagerung des würmzeitlichen Lösses (1) 1,0 - 1,3 $m$ unter der prälößzeitlichen Oberfläche und damit mit großer Sicherheit im Auftaubereich des ehemaligen (saalezeitlichen) und frühweichselzeitlichen Dauerfrostbodens. Während die im mittleren und unteren Teil des Maßstabs liegenden glazifluviatilen lehmigen Sande keine deutliche Frosteinwirkung erkennen lassen, hat offenbar der Gegensatz von sandig-lehmigen Schichten (3) und sandig-steinig-kiesiger Grundmoräne eine deutliche Kryoturbation begünstigt. Ergebnis sind viele recht kleine, aber deutliche Kiestaschen und von unten nach oben ragende "Sandspitzen“. Im linken Teil (Abb. 9) wurde die Schmutztapete von Schicht 2 entfernt. Die Kryoturbationsformen müssen entstanden sein, als der würmzeitliche Löß, der in das oberste Hochglazial (nach der Würmlößterminologie von SCHÖNHALS, SEMmel \& RoHDEnBurg 1964) gehört, noch nicht abgelagert war.

Die Taschenböden können demnach ab dem Drenthe-Stadium der Saale-Kaltzeit entstanden sein, nachdem das Eis hier abgetaut war (vor dem Rehburger Stadium). Die obere zeitliche Grenze dürfte, nach den Lößdeckschichten zu urteilen, einige tausend Jahre nach dem Brandenburger Stadium anzusetzen sein; denn der hangende Löß weist keine jungwürmzeitlichen Naßböden mehr auf. Es bleibt nochmals herauszustellen, daß sich mit Hilfe dieses Aufschlußbefundes ein maximal 1,2 - 1,3 m mächtiger Auftauboden des eiszeitlichen Permafrostbo- 


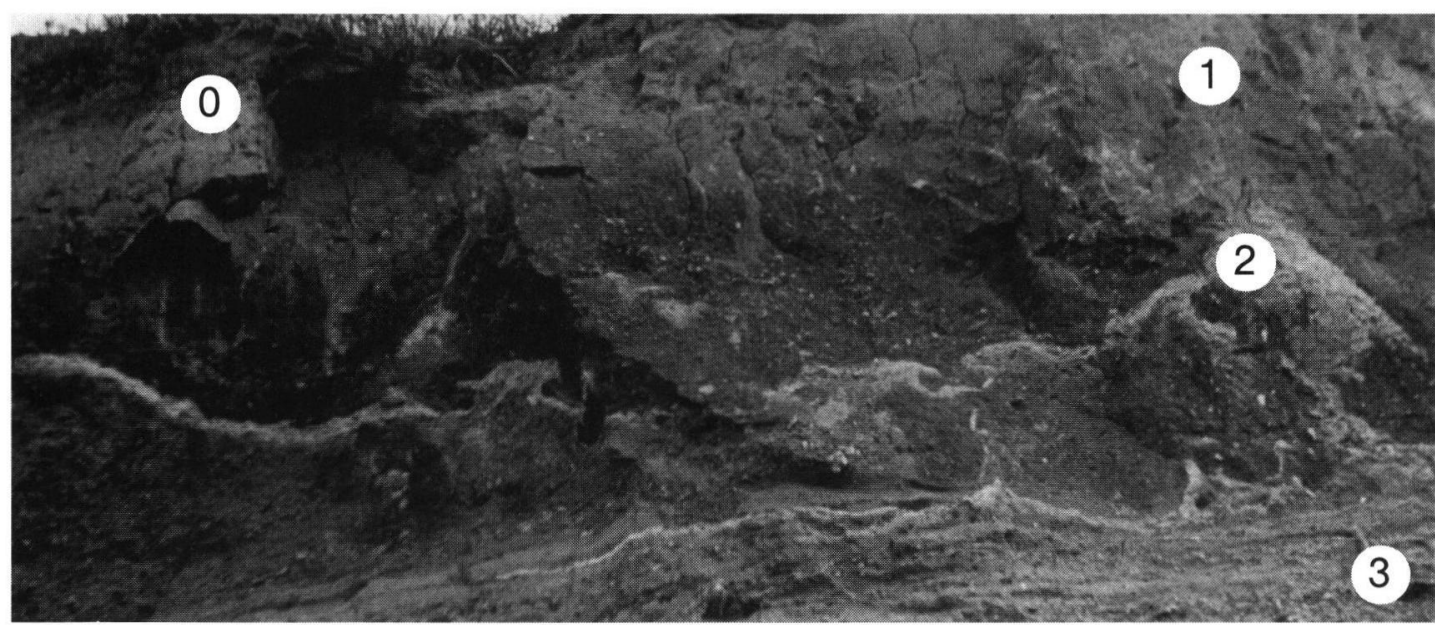

Abb. 11: Kryoturbationserscheinungen in und unter einer wahrscheinlich drenthezeitlichen Grundmoräne (2), an deren unterem Rand gelbe Schluffe ebenso auftreten (rechter Bildteil) wie in ihrem Inneren. Am Top würmzeitlicher Löß (1) mit dunklem Ap-Horizont (0), im Liegenden glazifluviatile Sande und Kiese (3). Lokalität: Kiesgrube zwischen Beierstedt und Watenstedt südl. der Eisenbahnstrecke. Foto Sommer 1966.

Fig. 11: Cryoturbation forms in and below a moraine of probably Drenthe age (layer 2); at the lower ridge of it and in the inner part of the moraine there can be seen a yellow loessic thin sediment. At the top wurmian loess (1) with dark Ap-horizon (0), in the lower part glacifluvial sand and gravel (3). Locality: Gravel exposure between Beierstedt and Watenstedt south of the railway line. Photo summer 1966.

dens erschließen läßt

Die Abbildung 10 zeigt, ebenfalls an der Nordwand der ehemaligen Sandgrube Evers bei Hötensleben aufgenommen, die gleiche Schichtenfolge wie Abb.

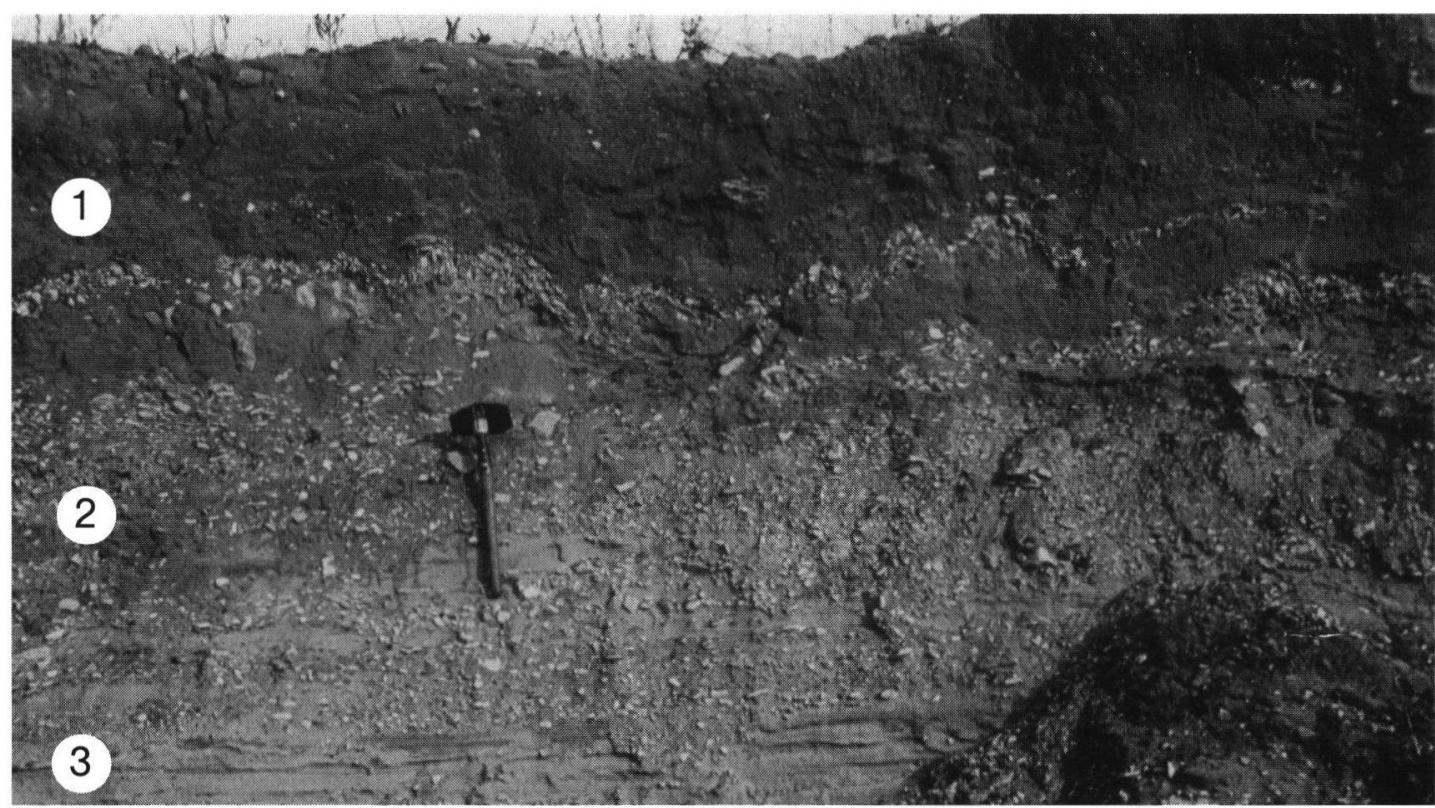

Abb. 12: „Girlandenboden“ in einer wahrscheinlich drenthezeitlichen Grundmoräne am Ausgang des Reitlingstales westl. des Elms bei Lucklum. Ein aus Muschelkalkbrocken bestehendes Band, das in die Moräne eingelagert ist, zeigt die Girlandenstrukturen. Im Liegenden (2) glazifluviatile Sande mit hohen Anteilen von Kalkschuttstücken, die von Osten her aus dem Elm herantransportiert wurden. Der Girlandenboden zeigt die intensive frostdynamische Bearbeitung der Grundmoräne an. Ehemals vorhandener Würmlöß im Hangenden künstlich abgeräumt. Foto Sommer 1965.

Fig. 12: "Girlandenboden" in a probably Drenthe moraine at the exit of the Reitlingstal west of the Elm near the village of Lucklum. A band of pieces of Muschelkalk, which is imposed in the moraine, shows the structures of guirlands. In the lower part (2) glacifluvial sands with a high percentage of chalk pieces, which were transported from the east to the west out of the Elm by the river Wabe. The "Girlandenboden" shows the intensive frost-caused movement of the moraine. A former existing loess at the top of the exposure had been put away by men. Photo summer 1965 
9 auf, nur mit unterschiedlichen Dicken des Decksedimentes (Löß) und der steinig-kiesig-lehmigen Grundmoräne. Im Bereich des Komplexes 1, der aus einem plattigen Ap-Horizont und einem B-Horizont der ehemals entwickelten Parabraunerde besteht, folgt ein gelber Löß (Schicht 2), der ins obere Hochwürm zu stellen ist. Die im linken Teil der Abbildung gut erkennbare steinig-kiesig-lehmige Grundmoräne (3) ist hier nur ca. $30 \mathrm{~cm}$ mächtig und dünnt zum rechten Bildrand hin auf $10 \mathrm{~cm}$ Dicke aus. Diese Grundmoräne zeigt in der Bildmitte eine Tasche, also einen Taschenboden. Die zum Schichtkomplex 4 gehörigen Sedimente: feine helle geschichtete Sande und bräunliche, etwas lehmige Sande, gehören dem oberen Teil der glazifluvialen Ablagerungen an. Wie die Abbildung 10 deutlich zeigt, sind sie ebenfalls von Kryoturbation erfaßt worden, wobei sie entweder leicht gewellt wurden oder spitzenförmig nach oben in die Grundmoräne eingewürgt wurden. Dieses Beispiel soll vor allem zeigen, daß die zeitliche Stellung des Kryoturbationsvorganges wie bei Abb. 9 einzustufen ist und daß auch hier die Verwürgungen bis in eine Tiefe von 0,8 - 1,0 m gewirkt haben - von der prälößzeitlichen Landoberfläche aus. Ein Teil der Grundmoräne dürfte hier vor der Ablagerung des Lösses bereits wieder abgetragen worden sein.

Das dritte Beispiel (Abb. 11), ebenfalls aus der Lößzone stammend, zeigt im Prinzip die gleiche Schichtenfolge wie das erste und zweite Beispiel von Kryo- turbationsformen. Heute existiert die Kiesgrube westlich Beierstedt zwischen Beierstedt und Watenstedt (südwestlich Schöningen) immer noch. Wichtig für die Identifizierbarkeit der Kryoturbationsformen ist die Tatsache, daß im rechten Bildteil am Top der wohlgeschichteten glazifluviatilen Kiese und Sande (3) ein helles Schluffband auftritt. Ein weiteres helles Schluffband durchzieht - was nur hier in dieser Deutlichkeit zu beobachten war - die Grundmoräne (2). Sowohl das untere Schluffband als auch das innermoränale Schluffband sind durch die frostdynamischen Prozesse intensiv verformt, z. T. gefaltet worden. An der Unterseite der Grundmoräne (2) entstanden im Bereich des unteren Schluffbandes, aber auch westlich davon, Taschenböden, innerhalb der Grundmoräne (2) dagegen ein klassischer "Girlandenboden", wie er wohl selten (wenn überhaupt) bisher abgebildet wurde. Daneben weist das Profil verschiedene Zeugnisse der Wühltätigkeit von Tieren (u. a. Krotowinen) auf. Zur Datierung der Kryoturbationsformen gelten die gleichen Aussagen, wie sie zu den Formen der Abb. 9 und 10 gemacht worden sind. Vor Ablagerung des späthochweichselzeitlichen Lösses mit seinem rezenten ApHorizont müssen die Schichtenstörungen gebildet worden sein. Da die Moräne mit hoher Wahrscheinlichkeit eine drenthezeitliche ist, kann die Zeitspanne des Einwirkens des eiszeitlichen Klimas ähnlich klar definiert werden wie bei den Formen der Kiesgrube Hötensleben. Die Tiefe des Auftaubodens

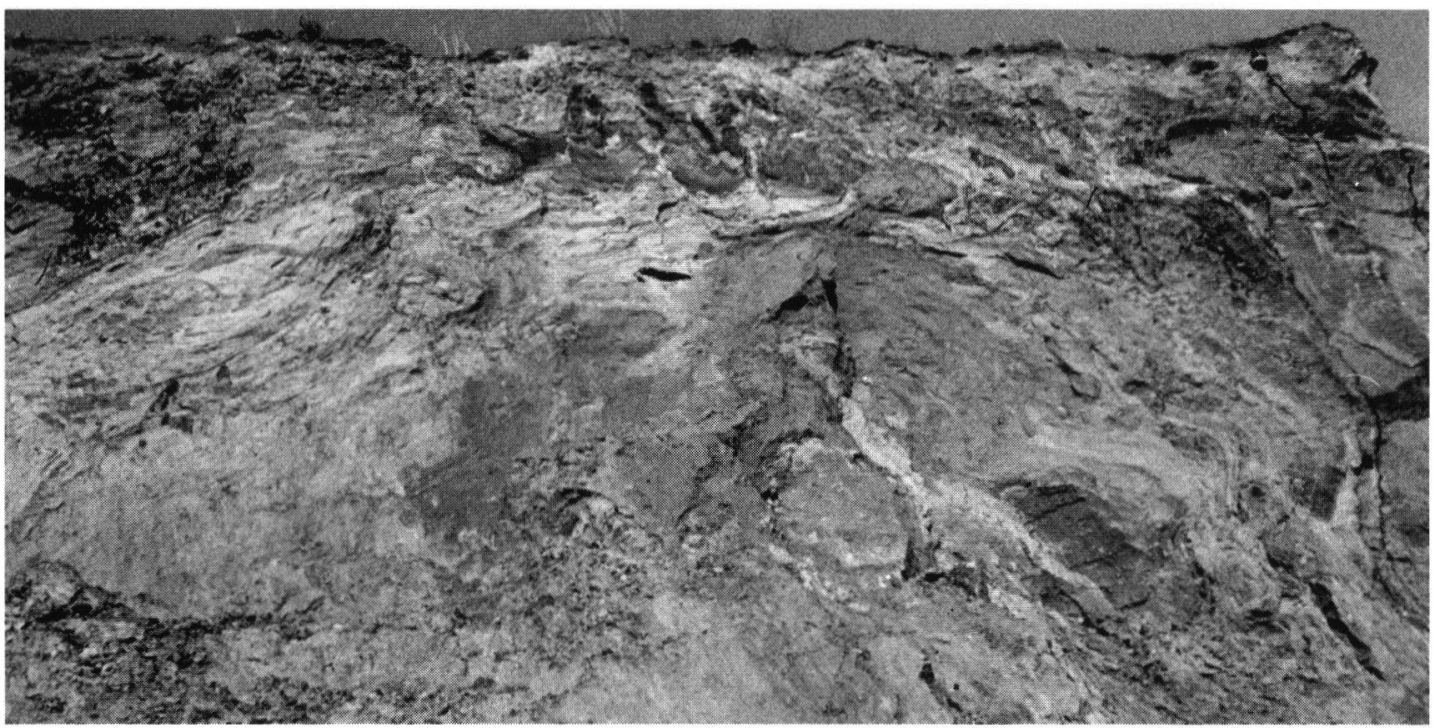

Abb. 13: Sandgrube südl. Weddel. Taschenboden in stark kryoturbiertem Horizont von 1,2 - 1,5 m Mächtigkeit. Korngrößenunterschiede zwischen Sand, lehmigem Sand und Lehm (dunkel) sind die Voraussetzung für das Wirken des kaltzeitlichen Frostes gewesen. Top einer glazigenen Stauchfalte wieder z. T. gekappt. Druck für Stauchfalte erfolgte von links (N) nach rechts (S). Foto Sommer 1966.

Fig. 13: Sand exposure south of Weddel. "Taschenboden" in heavily cryoturbated horizon of a thickness of 1,2 to 1,5 m. Differences in grain size between sand, loamy sand and loam (a bit dark) are the supposition for the action of the coldclimate frost action. The top of a glacigenic fold, also in this example, is cut by the younger denudation processes. Pressure for the folding occurred from the left hand side $(\mathrm{N})$ to the right hand side $(\mathrm{S})$. Photo summer 1966. 


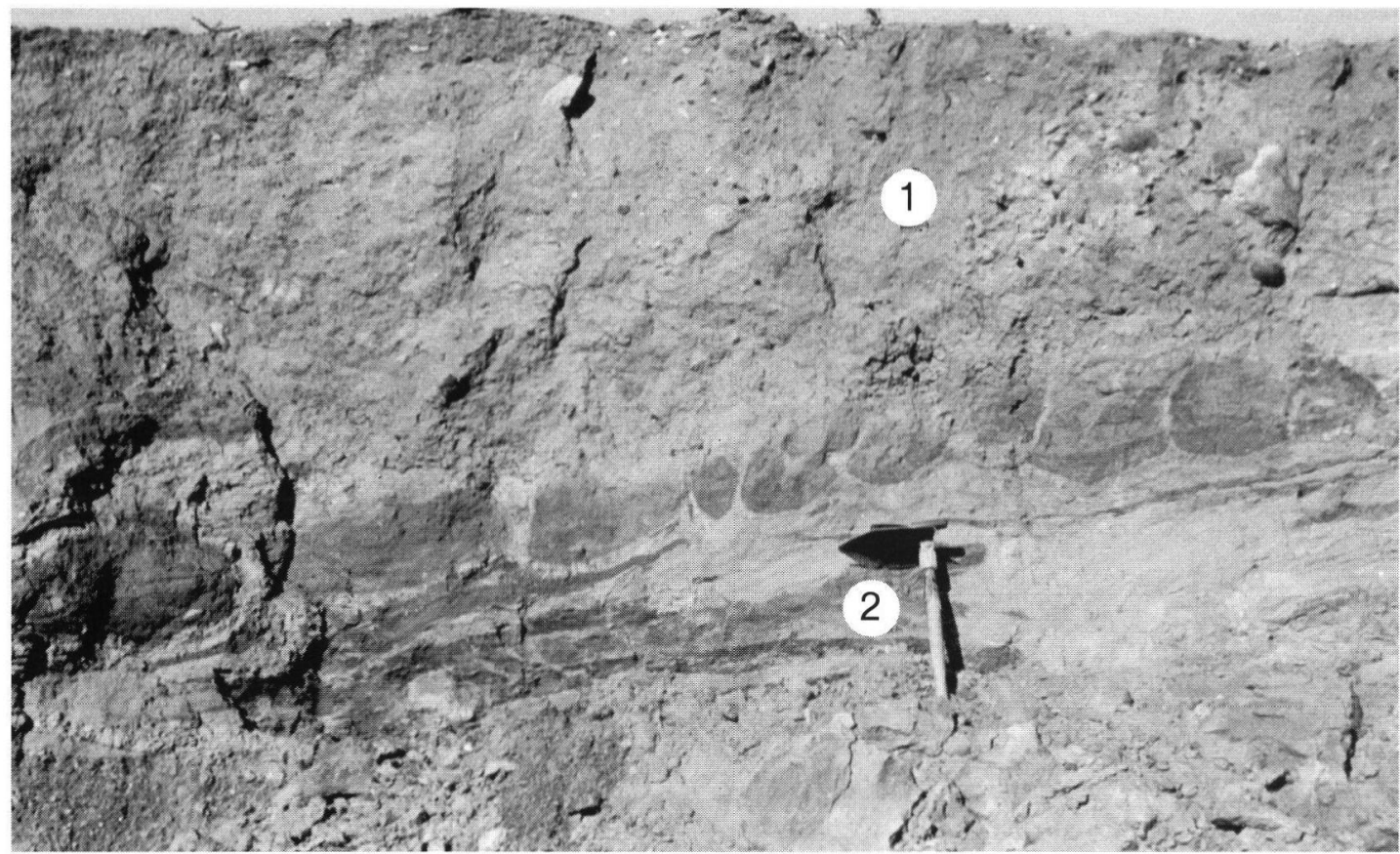

Abb. 14: Taschenboden in der ehemaligen Sand- und Kiesgrube westl. Heiligendorf (nördl. Königslutter am obersten Nordrand des Schuntertales). Im Top eine ca. $1 \mathrm{~m}$ mächtige, frostdynamisch beanspruchte Grundmoräne. Der Taschenboden beruht auf dem Schichtwechsel von Sand, lehmigem Sand und Schluff. Er zeigt die Eindringtiefe der frostdynamischen Beanspruchung an, die bis ca. 1,3 - 1,5 m Tiefe reichte. Foto Sommer 1966.

Fig. 14: "Taschenboden" in the former sand and gravel exposure west of Heiligendorf (north of Königslutter) at the upper ridge of the valley of the Schunter. At the top a ca. $1 \mathrm{~m}$ thick moraine, which shows former effected frost pressure. The "Taschenboden" is caused by the alternation of sand, loamy sand and silt. It shows, how deep the frostdynamic processes have reached downwards in the profile $(1,3$ to $1,5 \mathrm{~m})$. Photo summer 1966 .

dürfte hier eher zwischen 1,3 und 1,5 m gelegen haben (vgl. Maßstab rechts unten: ein Spaten).

Ein ganz ähnliches Beispiel eines „Girlandenbodens" wie westlich von Beierstedt fand sich in der ehemaligen Kiesgrube Lucklum 1,0 bis 1,5 km westlich des Westrandes des Elm. Am Südrand des Wabetales, durch welches das den Elm aufschließende Reitlingstal entwässert wird, wurden westlich der Bundesstraße Schöppenstedt - Braunschweig typisch lokal getönte glazifluviatile Schotter und Sande oder Flußschotter der Wabe (Schicht 2 in Abb. 12) mit hohen Muschelkalkanteilen aus dem Elm abgelagert. Diese umfassen den Bereich vom oberen Spatenende bis $0,5 \mathrm{~m}$ unterhalb des Spatens. Erst darunter sind typische glazifluviale, geschichtete Sande und lehmige Sande ohne bedeutende Kalkanteile anzutreffen (3). Oberhalb des Spatens treten auch hier wieder moränale sandig-lehmig-kiesige Sedimente (1) auf. Eine dünne weichselzeitliche Lößschicht wurde hier künstlich von Baggern abgeschoben. Da hier mitten in der Grundmoräne ein Schotterband aus Kalkstein und wenigen nordischen Gesteinen auftritt, waren günstige Voraussetzungen für das Entstehen von Kryoturbationserscheinungen gegeben. Ohne dieses Kiesband hätte man die deutliche Stauchung der Moränensedimen- te gar nicht erkannt. Die Auftautiefe des Dauerfrostbodens, der hier zweifelsfrei bestanden hat, dürfte vor der Lößablagerung auch hier zwischen 0,8 und 1,2 $\mathrm{m}$ betragen haben. Tiefere Einwirkungen der Frostdynamik sind in diesem Profil nicht erkennbar. Bezüglich der Datierung des Girlandenbodens bzw. der der gesamten Frosteinwirkung wären dieselben Schlüsse zu ziehen wie bei den bisher beschriebenen Profilen in diesem Kapitel.

Die Sand- und Kiesgrube südlich Weddel am östlichen Ortsrand von Klein-Schöppenstedt (östl. Braunschweig) wurde oben (Kap. 2) schon in anderem Zusammenhang behandelt. Die Abbildung 13 wurde hier schon vor längerer Zeit aufgenommen. Frische aktive Sandgruben bestehen hier jedoch heute noch weiter nördlich und östlich der in den 60er Jahren aufgeschlossenen Sandgrube, die das ehemalige Kalksandsteinwerk Weddel belieferte. Jüngste Grubenbegehungen lassen zwar noch Teile der oben behandelten Stauchungen erkennen, nicht aber mehr eindeutige frostdynamische Strukturen der Kryoturbation (Abb. 13). Wir befinden uns bei diesem länglichen plumpen Weddeler Berg, dem Höhenzug des Rehburger Stadiums, bereits nördlich außerhalb der Lößzone. Reste einer lehmig-steinigsandigen Grundmoräne überlagern hier glazifluvia- 
tile, von Norden her durch einen Gletschervorstoß gestauchte Sande, Kiese und lehmige Sande. Die frostdynamische Einwirkung nach Abtauen des Eises hat hier zu äußerst intensiven Schichtenstörungen (Taschen- und Nierenböden) geführt. Nicht ganz auszuschließen ist allerdings, daß im Rahmen der glazigenen Stauchung an einigen Stellen (z. B Abb. 13 rechts oben) moränales Material in die vorher abgelagerten glazifluvialen Sande eingestaucht worden ist. Die kryogene Einwirkung auf die Sedimente konnte hier während des ganzen restlichen Abschnitts der Saale-Vereisung nach Abschmelzen und während aller kalter Abschnitte der WeichselEiszeit erfolgen. Die Taschen-, Kissen- und Nierenböden reichen auch hier etwa bis 1,2 - 1,3 $\mathrm{m}$ hinab. Ebenfalls nördlich der nördlichen Lößgrenze liegt die ehemalige Sandgrube Heiligendorf am ehemaligen westlichen Ortsrand südlich der Straße Heiligendorf - Hattorf (nördl. Königslutter - vgl. Abb. 14). Diese Sand- und Kiesgrube, die früher wohl eher als Gemeindekiesgrube genutzt wurde, ist heute geschlossen bzw. weitgehend eingeebnet. Am Top des Aufschlusses wurde hier lediglich der ,Mutterboden" künstlich von einem Bagger abgeschabt. Es ergibt sich die gleiche stratigraphische Abfolge wie in allen übrigen in diesem Kapitel behandelten Aufschlüssen nördlich der nördlichen Lößgrenze: Unter einer lehmigen sandig-kiesig-steinigen Grundmoräne (1) folgen zunächst dünne Bänder heller Schluffe und dunklere, dickere Schichten lehmiger Sande (2), Während die eigentliche Grundmoräne auch schon kräftig frostgestaucht wirkte, hat die Kryoturbation besonders die - von der Korngröße her - heterogenen hellen Schluffe und lehmigen Sande (2) erfaßt. Ergebnis sind die schönsten Taschenböden des Untersuchungsgebietes und "Schluffspitzen“, die von unten nach oben bis an den Unterrand der Moräne empordrangen. Im linken Teil des Bildes, in dem die Grenzschicht von Komplex $1 \mathrm{zu}$ Komplex 2 tiefer als im rechten Bildteil liegt, sind dagegen keine deutlichen Kryoturbationsformen mehr zu erkennen. Dieser Umstand weist darauf hin, daß die Wirkungszone der frostdynamischen Prozesse des Tauens und Gefrierens über einem Dauerfrostboden auf den oberflächennahen Bereich zwischen 1,0 - 1,3 m Tiefe beschränkt gewesen sein muß. Da wir uns mit dem Nordrand der Sandgrube Heiligendorf nahe der nördlichen Kante des nördlichen Schuntertalhanges befinden, dürfte mit keiner großen Abtragung der hangenden Schichten zu rechnen sein. Bezüglich

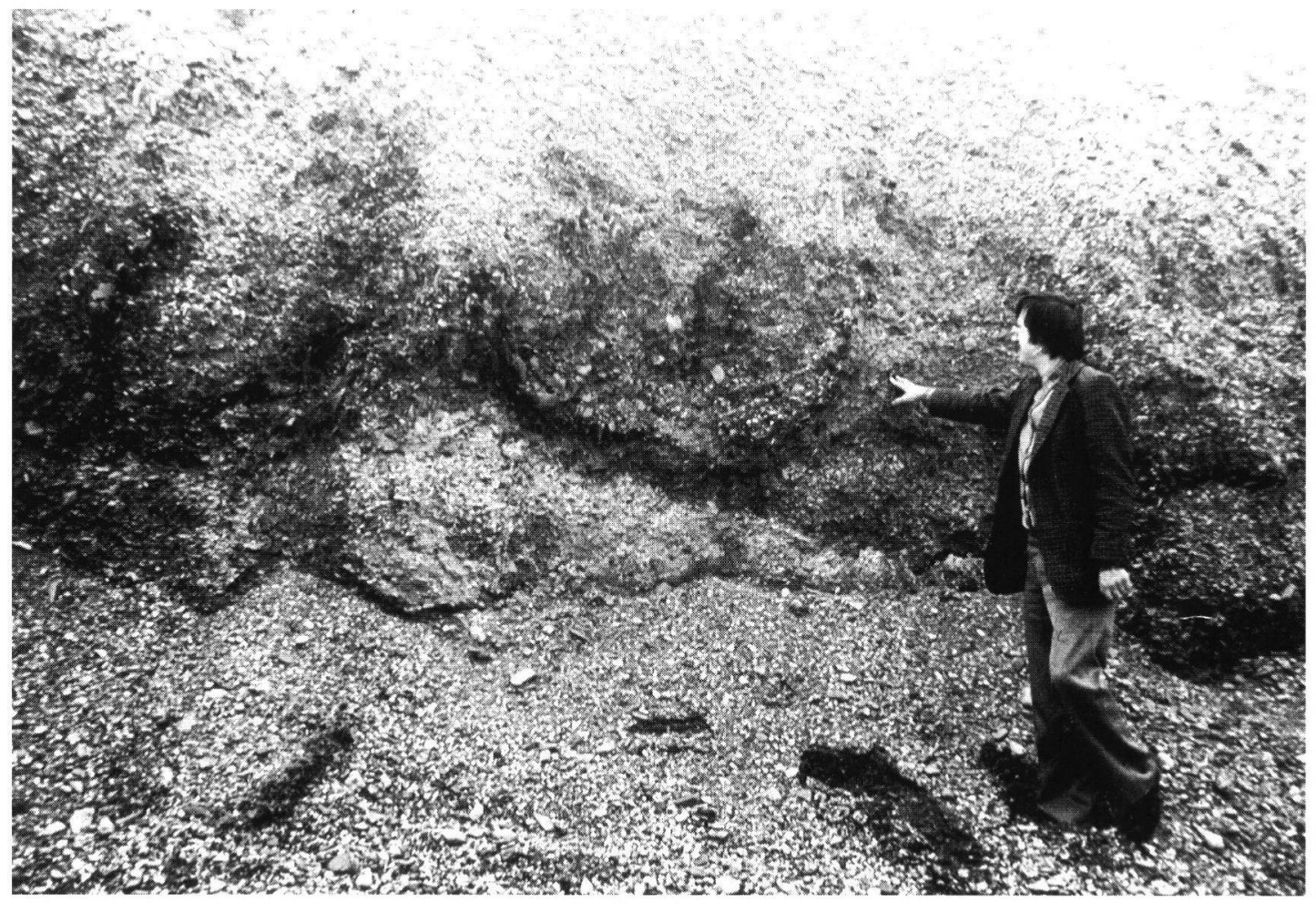

Abb. 15: Starke Einwirkungen der Kryoturbation in glazifluvialen Sedimenten im Oberterrassenniveau des Weddebaches nördl. Weddingen (westnordwestlich Vienenburg). Kryoturbation griff bis in $1,5 \mathrm{~m}$ Tiefe hinab und schuf Kiestaschen in weitgehend homogenem Kiesmaterial mit Kantenstellung der Kiese. Foto Sommer 1977.

Fig. 15: Strong influence of cryoturbation in glacifluvial sediments in the level of the upper terrace of the Weddebach north of Weddingen (westnorthwest of Vienenburg, near Goslar). The cryoturbation reached down to a depth of $1,5 \mathrm{~m}$ and formed pockets of gravel in a mostly homogenious gravel material. The stones are erected. Photo summer 1977. 


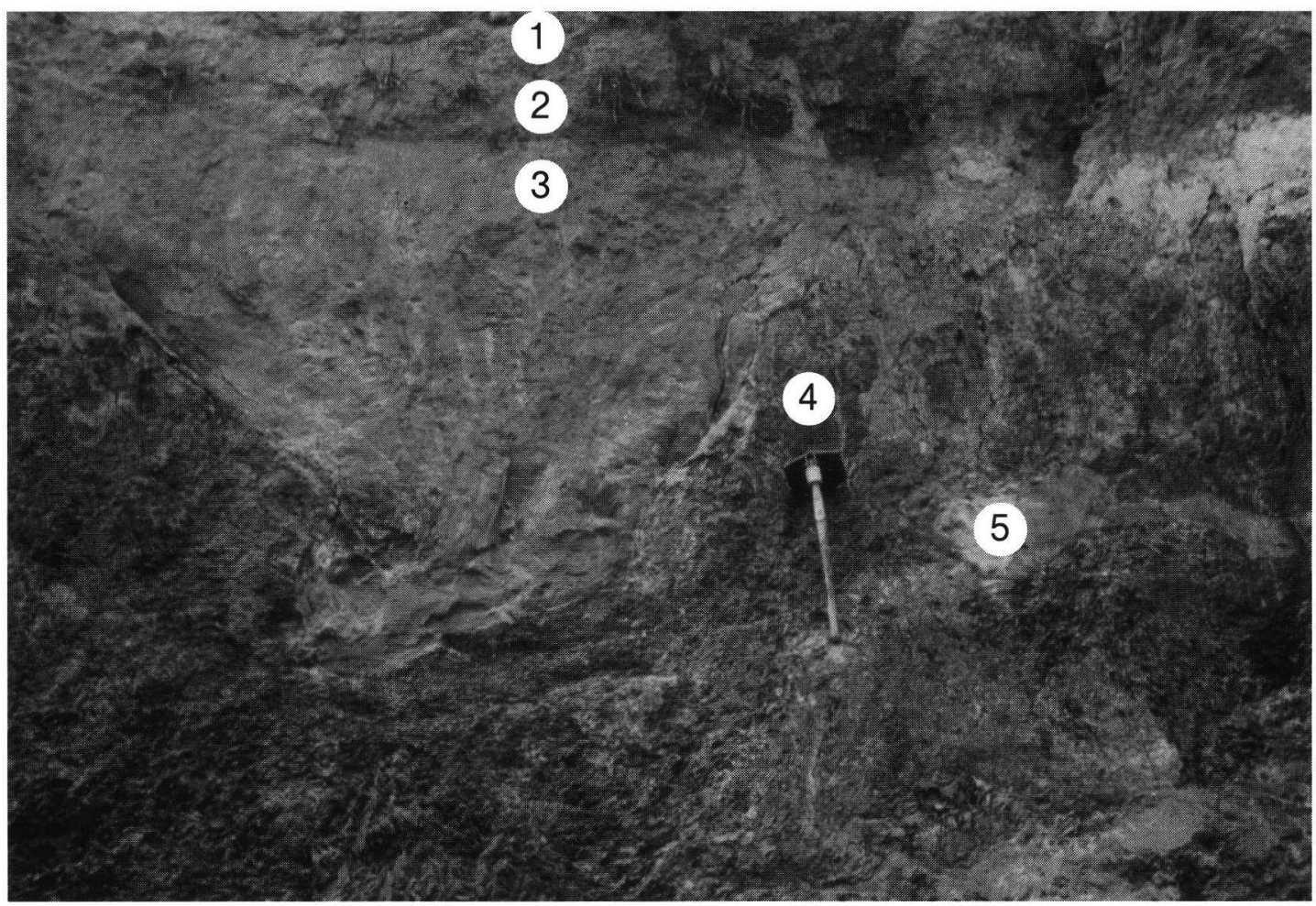

Abb. 16: Einzigartiger Wannenboden in der ehemaligen Ziegeleigrube Grasleben im Allertalgraben nördl. Helmstedt. Schicht 1 ist Abraum, Schicht 2 markiert den holozänen Boden. Das helle sandig-lehmige Material (Schicht 3), mit einigen nordischen Geschieben durchsetzt, ist eine lokal geprägte Grundmoräne, die durch intensive frostdynamische Aktivität mit dem bis in 1,5 - 1,6 m Tiefe aufgeweichten schwarzen Liaston (4) verknetet ist. Dabei entstanden Wannenböden von maximal 1,3 m Tiefe und isolierte „Moräneninseln“ von unterschiedlicher Größe (Schicht 5). Foto Sommer 1963.

Fig. 16: Singular "Wannenboden" in the former brick pit of Grasleben in the Allertalgraben, north of Helmstedt. Layer 1 is artificially thrown out earth, layer 2 marks the Holocene soil. The light sandy loamy material (layer 3), containing some pieces of Skandinavian material, is a local moraine, which is kneated together with dark Liassic clay (layer 4) by intensive frostdynamic actions down to a depth of 1,5-1,6 m. Through this frost action there were formed many "Wannenböden" with a maximal depth of 1,3 $\mathrm{m}$, and isolated "isles" of morainic material of different growth (layer 5). Photo summer 1963.

der zeitlichen Stellung der Taschenböden von Heiligendorf gelten dieselben Überlegungen wie für die Vorkommen von Weddel/Kl. Schöppenstedt.

Außer in der Kiesgrube östlich Isingerode am Osthang des Okertales fand ich ein Beispiel für starke Kryoturbationserscheinungen in mehr oder weniger homogenem Flußschottermaterial im Oberterrassenniveau des Weddebaches nördl. Weddingen nordwestlich des Harliberges (nördl. Bad Harzburg bzw. Vienenburg - vgl. Abb. 15). Eine dünne Lößdeckschicht ist hier künstlich entfernt worden. Eine intensive Froststauchung hat hier in der Kiesgrube Weddingen bis in Tiefen von 1,3-1,5 $\mathrm{m}$ Tiefe hinabgegriffen, wobei trotz der Homogenität des Materials große Taschen entstanden. Diese Taschen sind vor allem an der intensiven Kantenstellung der sie begrenzenden Steine erkennbar. In erheblichem Umfang wurde hier einerseits Material von unten nach oben, andererseits von oben nach unten bewegt. Bezüglich der zeitlichen Einordnung der Formen bleibt anzumerken, daß in diesem Falle seit der
Elster-Kaltzeit, in der mit großer Wahrscheinlichkeit die Kiese aufgeschüttet worden sind, über längere Zeiträume hinweg die Möglichkeit zur frostdynamischen Einwirkung des Klimas auf die Sedimente bestanden hat, sofern keine Lößdecke das Eindringen der frostdynamischen Prozesse bis zu den angegebenen Tiefen verhinderte.

Die bei weitem beeindruckendsten Einflüsse des kaltzeitlichen Klimas wurden in der ehemaligen Ziegeleigrube Grasleben an der Straße Grasleben Querenhorst angetroffen (Abb. 16). Schwarze Liastone, die zusammen mit allen Gesteinen des Mesozoikums bis zum Oligozän und Miozän im bis zu 2 $\mathrm{km}$ breiten Zerrgraben des Allertals über dem Gipshut eingesunken sind, wurden hier in der Nachkriegszeit bis zum Ende der 60er Jahre abgebaut. Sie sind durch die tektonischen Ereignisse im Rahmen der saxonischen Gebirgsbildung allerdings nicht makroskopisch beeinflußt worden. Jedoch ist die gesamte Abbauwand in ihren obersten 1,5 bis 1,6 Metern völlig aufgemürbt, sofern die Liastone anste- 
hen. Über den schwarzen Liastonen trifft man in einigen Dezimetern Mächtigkeit eine grau-orangefarbene sandige, schwach lehmige Grundmoräne mit wenigen Steinen an. Die gesamten Wände weisen nun in einmaliger Weise tiefe, moränengefüllte Wannen- und Taschenböden auf, deren Dimensionen sonst nirgendwo erreicht wurden. Die grauen Farben rechts der Zahl 4 in Abb. 16 sind von Schmutz verursacht worden. Der größte Wannenboden wurde in der Abbildung mit einer schwarzen Linie umrandet. Die Moräne selbst machte - ebenso wie der Liaston - bis in 1,6 m Tiefe einen stark verkneteten Eindruck. Als Besonderheit treten immer wieder isolierte Moränenflecken (5) im aufgemürbten, zerkneteten Liaston (4) auf. Ganz unten im Bild ist dagegen unterhalb der größten Wanne der noch völlig ungestörte Liaston erkennbar, der freilich wie Schiefer Einflüsse von Brüchen aus mehreren Richtungen aufweist. Wir befinden uns bereits außerhalb der Lößzone, so daß hier in der Umgebung lediglich ein Geschiebedecksand an der Oberfläche auftritt, auf dem eine Braunerde entwickelt ist. Der hohe Sandanteil der Grundmoräne erklärt sich aus der Tatsache, daß nördlich der Ziegeleigrube flächenhaft eozäner heller Sand ansteht, der bis heute als Glassand für die Döhrentruper Glaswerke in Grünenplan (Ith-Hils-Gebiet) dient. Wollte man annehmen, daß die riesigen Wannen-, Taschen- und Kesselböden nicht kryogenen Ursprungs im Sinne von Kryoturbationsformen, sondern eher glazigenen Ursprungs im Sinne der direkten Einwirkung von Inlandeisdruck sind, so stünde man vor der Frage, ob das Eis in der Lage war, seine Grundmoräne über Dauerfrostboden in die Liastone zu drücken. Ich neige zu der Deutung, die auch bei der Erklärung von Tropfenböden (Kerkoboloiden) angewandt wird: Der 1,5 - 1,6 $m$ tief hinabgreifende Auftauboden über dem ehemaligen permafrost table muß infolge des Liastones so wassergesättigt und beweglich gewesen sein, daß Teile der Grundmoräne, wahrscheinlich dort, wo sie etwas mächtiger als in der Umgebung waren, regelrecht in den wassergesättigten Ton eingesunken sind. Diese Vorstellung ist auch deshalb wahrscheinlich, weil in mehreren Aufschlüssen bei einer Sandbasis die Grundmoräne an ihrer Unterseite häufiger kleine Eindellungen aufweist (s. o. S. ), die zu Mächtigkeitsunterschieden der Grundmoräne auf kurze Distanz führen (zuletzt im Februar 1995 in der Everschen Sand- und Kiesgrube am Nordschacht westl. Helmstedt beobachtet). Für die Datierung dieser Kryoturbationsformen besonderen Typs gelten die gleichen Überlegungen wie bei den übrigen Lokalitäten außerhalb des Lößgebietes.

\section{Schriftenverzeichnis}

Bartels, G. \& Rohdenburg, H. (1968): Fossile Böden und Eiskeilhorizonte in der Ziegeleigrube Breinum und ihre Auswertung für die Reliefentwicklung im Jungquartär. - Göttinger Bodenkundliche Berichte, 6: 109 126; Göttingen.

Brosche, K.-U. (1964): Über Periglazialerscheinungen im Lappwald und in seinem nächsten Vorland. - Seminararbeit Universität Göttingen, angefertigt bei Prof. Dr. H. Poser, unveröffentlicht: 80 S.; Göttingen.

- (1968): Struktur- und Skulpturformen im nördlichen und nordwestlichen Harzvorland. - Göttinger Geographische Abhandlungen, 45: 236 S., 2 Textabb., 10 Beilagen; Göttingen.

- (1969): Über die Beziehungen von Rumpfflächen zu Schichtkämmen und Schichtstufen sowie Beobachtungen an einigen wichtigen Strukturformtypen, erläutert an Beispielen aus dem nördlichen und nordwestlichen Harzvorland. - Zeitschr. f. Geomorph., 13: 207-216; Berlin.

Brosche, K.-U. \& WaLther, M. (1978): Die jungpleistozänen Lößdeckschichten der Braunkohlentagebaue der Braunschweigischen Kohlenbergwerke (BKB) zwischen Helmstedt und Schöningen. - Eiszeitalter und Gegenwart, 28: 51-67; Öhringen.

- (1991): Untersuchungen zur Lößstratigraphie und jungpleistozänen Formung in Südniedersachsen und im östlichen Westfalen. - Geographica - Oekologica Arbeiten zur Geographie und Ökologie, 2: 52 S., 13 Abb., 2 Karten, 7 Fotos auf 3 Tafeln; Berlin.

BRÜNING, H. (1956): Fossile Frostbodenerscheinungen aus dem Stadtgebiet von Magdeburg und aus der Magdeburger Börde. - Hallesches Jahrbuch für Mitteldeutsche Erdgeschichte, 2, 3: ; Halle.

- (1957): Eiszeitliche „Klein-Frostbodenformen“ im Talrandlöß von Magdeburg. - Hallesches Jahrbuch für Mitteldeutsche Erdgeschichte, 2, 4:; Halle.

- (1958): Museumsarbeit in den Baugruben einer Großstadt. - Der Präparator, Zeitschrift für Museumstechnik, 4: Magdeburg.

- (1959): Periglazialerscheinungen und Landschaftsgenese im Bereich des mittleren Elbetales bei Magdeburg. - Studien über die Periglazialerscheinungen in Mitteleuropa, herausgegeben von Hans Poser, Göttinger Geographische Abhandlungen, 6 Abb., 18 Fig. als Beilagen, 80 S.; Göttingen.

Goedecke, R. (1966): Die Oberflächenformen des Elm. Göttinger Geogr. Abhandlungen, 35; Göttingen.

Hempel, L (1955): Frostbodenbildung und Lößanwehung in der Würmeiszeit auf Muschelkalk und Buntsandstein bei Göttingen. - Abhandlungen der Akademie d. Wiss. u. d. Lit. in Mainz. Math.-naturwiss. Kl. Jhg. 1955 Nr. 2; Mainz.

Herrmann, R. (1929): Erdgeschichtliche Grundfragen der Oberflächenformung in Mitteldeutschland. Festschrift des 23. Deutschen Geographentages in Magdeburg, hrsg. von O. SCHLÜter \& E. Blume: 71-108; Braunschweig/Berlin/Hamburg.

KaISER, K. (1960): Klimazeugen des periglazialen Dauerfrostbodens in Mittel- und Westeuropa. - Eiszeitalter und Gegenwart, 11: 121 - 141, Öhringen (Rau). - (1966): Das Quartär zwischen Harz und Elbe. - Eiszeitalter und Gegenwart, 17: 200-204; Öhringen.

Keilhack, K. (1931): Über „atektonische Faltung“ (Stiche) in der Trias des Harzvorlandes und über einen merkwürdigen Fall des Hakenschlagens. - Zeitschr. d. Dtsch. Geol. Ges., 83

LiedTKe, H. (1975): Die nordischen Vereisungen in Mitteleuropa. - Forschungen zur Deutschen Landeskunde. 204; Bonn - Bad Godesberg. 
LoOK, E. R. (1968): Geologisch-stratigraphische Untersuchungen in Sedimenten der Elster- und Saale-Eiszeit (Pleistozän) am Elm, östlich Braunschweig. - Mitteilungen aus dem Geologischen Institut der Technischen Hochschule Hannover, 6: 108 S., 18 Abb., 4 Tab., 27 Taf.; Hannover.

- (1984): Geologie und Bergbau im Braunschweiger Land. - Berichte der Naturhistorischen Ges. Hannover, 127: 1-467; Hannover.

LudwIG, A. (1958): Beobachtungen im Pleistozän des nordöstlichen Harzvorlandes. - Geologie, 7: 769-793; Berlin.

ManiA, D. \& Toepfer, V. (1973): Königsaue; Gliederung, Ökologie und mittelpaläolithische Funde der letzten Eiszeit. - Veröffentlichungen des Landesmuseums f. Vorgeschichte Halle, 26: 164 S.; Halle.

ManiA, D. (1965): Stratigraphie, Genese und Palökologie des Quartärs in der Ascherslebener Depression und ihrer Umgebung. - Diss. Halle.

- (1967): Das Jungquartär aus dem ehemaligen Ascherslebener See im Nordharzvorland. - Petermanns Geographische Mitteilungen, 111: 257 - 273; Gotha. - \& STeChemesser, H. (1970): Jungpleistozäne Klimazyklen im Harzvorland. - Petermanns Geographische Mitteilungen, Erg.-Heft, 274: 39-55; Gotha.

MERKT, J. (1968): Erläutcrungen zur Karte der Lößverbrei tung in Südniedersachsen. - Geol. Jahrbuch, 86: 107112: Hannover.

Poser, H. (1947 a): Dauerfrostboden und Temperaturverhältnisse während der Würmeiszeit im nicht vereisten Mittel- und Westeuropa. - Naturwissenschaften, 34: 1018; Berlin.

- (1947 a): Auftautiefe und Frostzerrung im Boden Mitteleuropas während der Würm-Eiszeit. - Naturwissenschaften, 34: 262-267 und 323-328; Berlin.

- (1948 a): Boden- und Klimaverhältnisse in Mittelund Westeuropa während der Würm-Eiszeit. - Erdkunde, 2: 53-68; Bonn.

- (1948 b): Äolische Ablagerungen und Klima des Spätglazials in Mittel- und Westeuropa. - Naturwissenschaften, 9: 269-275 und 307-312; Berlin.
- (1951): Die nördliche Lößgrenze in Mitteleuropa und das spätglaziale Klima. Eiszeitalter und Gegenwart, 1: 27-55; Öhringen (Rau).

ROHDEnBurg, H. (1965): Die Muschelkalk-Schichtstufe am Ostrand des Sollings und Bramwaldes. - Göttinger Geogr. Abh., 33; Göttingen.

- (1966): Eiskeilhorizonte in südniedersächsischen und nordhessischen Lößprofilen. - Mitteilungen d. Deutschen Bodenkundl. Ges., 5: 137-170; Göttingen.

- (1968): Jungpleistozäne Hangformung in Mitteleuropa. - Beiträge zur Kenntnis, Deutung und Bedeutung ihrer räumlichen und zeitlichen Differenzierung. - Göttinger Bodenkundl. Berichte, 6: 3-107; Göttingen.

- \& MeYer, B. (1966): Zur Feinstratigraphie und Paläopedologie des Jungpleistozäns nach Untersuchungen an südniedersächsischen und nordhessischen Lößprofilen. - Mitteilungen der Deutschen Bodenkundl. Gesellschaft, 5: 5-131; Göttingen.

Schönhals, E.; Semmel, A. \& Rohdenburg, H. (1964): Ergebnisse neuerer Untersuchungen zur Würmlöß-Gliederung in Hessen. - Eiszeitalter u. Gegenwart, 15: 199-206; Öhringen.

Walther, M. (1979): Verbreitung und Stratigraphie letzteiszeitlicher Lößfolgen in der norddeutschen Lößzone südlich der nördlichen Verbreitungsgrenze bis zu den Mittelgebirgen hin (Nordrhein-Westfalen, Südniedersachsen), - Schriftliche Staatsexamensarbeit, Wiss. Landesprüfungsamt Berlin; Berlin.

Walther, M. \& Brosche, M. (1983): Zur Bedeutung der Lößstratigraphie für die Rekonstruktion des jungpleistozänen Klimas im nördlichen Mitteleuropa am Beispiel norddeutscher Lößprofile. - Ber. naturhist. Ges. Hannover, 125: 97-159; Hannover.

Washburn, a. L. (1979): Geocryology. - A survey of periglacial processes and environments. 406 S., London.

WOLDSTEDT, P. \& DUPHORN, K. (1974): Norddeutschland und angrenzende Gebiete im Eiszeitalter; Stuttgart.

Manuskript eingegangen am 15. 12. 1994 